\title{
Situations, alternatives, and the semantics of 'cases'
}

\author{
Friederike Moltmann ${ }^{1}$
}

Published online: 12 December 2019

(C) The Author(s) 2019

\begin{abstract}
This paper argues that NPs with case as head noun stand for situations in their role as truthmakers within a sentential or epistemic case space. The paper develops a unified semantic analysis of case-constructions of the various sorts within a truthmaker-based version of alternative semantics.
\end{abstract}

Keywords Situation semantics - Situations - Alternative semantics · Association with focus · Truthmaker semantics · Propositional attitudes · Clausal complements

Situations have come to play a significant role in semantic theory. They have been advocated as an alternative to possible worlds for a more fine-grained notion of sentence meaning, in situation semantics (Barwise and Perry 1981; Kratzer 2014) and, more recently, truthmaker semantics (Fine 2012, 2014, 2017), or else for the analysis of particular linguistic phenomena, such as perception reports, definite descriptions, E-type pronouns, conditionals, adverbs of quantification and generic sentences. Yet while situations are generally considered important for semantics, their semantic role is generally considered an implicit one, with situations acting as parameters of evaluation, implicit arguments, or truthmakers, but not as semantic values of referential NPs.

This paper is about constructions that do involve explicit reference to situations, namely noun phrases with the noun case as head (case-NPs). Case-NPs, this paper will argue, involve reference to situations in their role as truthmakers within a space of alternatives, that is, 'cases'. Case-constructions in English (and corresponding constructions in other languages) take the form of NPs with case as head noun and a

Friederike Moltmann

fmoltmann@univ-paris1.fr

1 CNRS, Paris, France 
clausal modifier (a case-clause) as in (1), of case-anaphora as in (2), and of the predicate is the case, as in (3):

Case-NPs with a case-clause as modifier

(1) a. the cases in which a student failed the exam

b. the case in which it might rain tomorrow

Case-anaphora

(2) a. John might go to the party. In that case, I will go too.

b. If John has lost, Mary is happy. In that case, she will celebrate.

c. Mary claims that John has won the race. In that case, we will celebrate.

The predicate is the case

(3) It is sometimes the case that a student fails the exam.

In addition to clausal case-NPs as in (1), there are nominal case-NPs, such as the case of the stolen statue and a case of $f l u$, which share significant similarities with clausal case-NPs. They will not be the focus of this paper, however, but addressed only in an appendix (Appendix 1).

The paper outlines a semantic analysis of case-constructions that is cast within a development of truthmaker semantics in the sense of Fine $(2012,2014,2017)$ and alternative semantics (Hamblin 1973; Rooth 1992; Kratzer and Shimoyama 2002; Aloni 2007; Ciardelli et al. 2017; Santorio 2018), the view that a sentence may stand for several alternatives at once. More specifically, the analysis is based on two overall claims:

[1] Case-constructions involve actual or possible (or even impossible) situations in their role as truthmakers of sentences in the sense of Fine's truthmaker semantics. ${ }^{1}$

[2] Case-constructions involve situations only within a case space, a set of alternative situations (or kinds of situations) which are either the truthmakers of a sentence or the truthmakers of an epistemic state of uncertainty associated with the use of the case-construction.

Case-constructions bear on a range of other issues in philosophy of language and natural language semantics besides truthmaker semantics and alternative semantics, in particular the ontology of situations and related categories of entities, the nature and range of kind reference, actuality or existence entailments of lexical items, the semantics of conditionals and its involvement of situations, and the relation of the predicate is the case to the truth predicate is true.

While not all languages have case-constructions, a noun for 'case' appears in more or less the very same constructions in a range of European languages, including German (Fall), French (case), Italian (caso), and Spanish (caso). Some of the important properties of case-constructions are displayed more transparently in other languages than English, which this paper will then make use of.

\footnotetext{
${ }^{1}$ Fine's notion of a truthmaker in 'truthmaker semantics' differs from the notion of a truthmaker in metaphysics. The former has a purely semantic purpose, the latter a metaphysical one, namely that of grounding truth. See Appendix 2 for discussion.
} 
The paper will first argue for the involvement of situations as exact truthmakers in case-constructions and present an outline and extension of truthmaker semantics. Second, it will show the involvement of a case space in case-constructions and outline a semantic analysis of case-constructions of the various sorts based on a truthmakerbased version of alternative semantics. Appendix 1 will be about the semantics of nominal case-constructions; Appendix 2 will discuss the relation of the notion of a truthmaker involved in case-constructions to the philosophical truthmaker debate.

\section{Situations, quantification over cases and reference to kinds of cases}

The overall view this paper develops is that cases, the entities case-constructions make reference to, are situations (or kinds of situations) in their role as truthmakers, and that within a space of alternative situations (or kinds of situations), a 'case space'. This section will focus on the first part, situations in their role as truthmakers; the next section will focus on the involvement of a case space in the semantics of case-constructions.

\subsection{The ontology of cases}

Let me start with clarifying the ontology of situations, the entities that can play the semantic role of truthmakers. Situations are considered primitives and fully specific parts of actual, possible, or even impossible worlds. Situations involve entities having properties or standing in relations to other entities, at a particular time or time-independently. Such entities form the domain of a situation. Situations need not involve a continuous temporal or spatial location.

Situations that may be cases need to be distinguished from other, related sorts of entities. First of all, situations are not on a par ontologically with events and states. ${ }^{2}$ Events and states may be in situations and thus be part of the domain of a situation, but not vice versa. Events and states have a duration and thus may last for a time, but not so for cases. Cases differ from events and states also in the sorts of existence predicates they may accept. ${ }^{3}$ Events do not go along with the existence predicate exist, but only with event-specific existence predicates such as happen and take

\footnotetext{
${ }^{2}$ Fine calls the entities that play the truthmaker role 'states' rather than 'situations'. Fine's notion of a state is a technical one and has little to do with states as referents of state-referring terms ((the state of) John's being tired) and as the entities that stative predicates (lie, stand, weigh, believe) describe.

${ }^{3}$ Existence predicates form a semantically characterizable class of predicates in natural language. What distinguishes them from other types of predicates is that they may yield true sentences with a subject not standing for an actual entity and a negated predicate, as is illustrated with exist below:

(i) Vulcan does not exist.

Existence predicates also include occur, happen, take place, and obtain. See Moltmann ( 2013b, 2018b) for a discussion of existence predicates in natural language.
} 
place. Happen and take place are not applicable to cases. ${ }^{4}$ Only the existence predicate occur is applicable to cases, more precisely kinds of cases (as in The case in which a student passed the exam has never occurred). States go along with the existence predicate obtain or even exist (as in The state of war still obtains/exists). But neither obtain nor exist is applicable to cases.

The situations that case-constructions make reference to are situations that are fully specific parts of possible (or even impossible) worlds. They are thus on a par with worldly facts in the sense of Austin $(1950,1961)$, rather than non-worldly facts in the sense of Strawson (1949). ${ }^{5}$ Non-worldly facts are entities that stand in a 1-1relation to true propositions and are describable by fact descriptions of the sort the fact that $\mathrm{S}$ (however non-worldly facts may be conceived ontologically). ${ }^{6}$ Clearly, case-NPs do not stand for possible non-worldly facts. Case-NPs with existentially quantified case-clauses as below make this particularly clear:

(4) a. several cases in which a student passed the exam

b. the three cases in which a student passed the exam

If several students passed the exam, then there are several cases in which a student passed the exam, not a single case in which a student passed the exam. This permits a suitable quantifier domain for (4a) and plural referent for (4b). By contrast, if several students passed the exam, there will still be only a single nonworldly fact described by the fact that a student passed the exam. Also disjunctions make the difference between cases and non-worldly facts apparent and show that cases take the role of truthmakers rather than being constituted by true propositions. A true disjunction such as $S$ or $S^{\prime}$ will correspond to exactly one non-worldly fact, describable as the fact that $S$ or $S^{\prime}$. By contrast, there will be as many cases as there are situations making either disjunct true. This then allows the use of the plural and a numeral in the examples below:

(5) a. the cases in which Mary has received an invitation or John has received one b. the two cases in which it rains or it snows

Cases, being fully specific truthmakers, cannot be existentially quantified or disjunctive.

\footnotetext{
${ }^{4}$ Natural languages generally display different existence predicates for different sorts of entities. Thus, exist applies to material and abstract objects (or empty terms describing them) as in (ia), but not to events, as seen in (ib):

(i) a. The number four exists.

b. ??? The accident existed yesterday.

These semantic selectional restrictions can be traced to exist and occur conveying different ways in which entities relate to space and time (Moltmann 2013b, 2018b).

5 For the distinction between worldly and non-worldly facts see also Fine (1982).

${ }^{6}$ For an ontological account of non-worldly facts as pleonastic entities or entities abstracted from true sentences see Moltmann (2013a, Chap. 6).
} 
Cases moreover do not share the existence predicate specific to non-worldly facts, namely obtain. The fact that a student passed the exam may 'obtain', but not so for the case in which a student passed the exam.

Cases that have the status of future epistemic alternatives may come with a special 'case'-specific existence predicate. Most strikingly, German chooses eintreten 'to enter' and French se produire 'produce itself' as the existence predicate reserved for cases of that sort $^{7}$ :

(6) a. Der Fall, dass Hans zurückkommt, ist nicht eingetreten.

'The case that John returns did not enter.'

b. Le cas ou Jean retourne ne s'est pas produit.

'The case where John returns did not produce itself.'

Eintreten and se produire as existence predicates apply to no other kind of entity (except to a very restricted class of events, such as deaths). In English, present itself can be used as an existence predicate specific to future epistemic alternatives.

Cases as epistemic alternatives differ from entities referred to as 'possibilities' with respect to the attribution of existence. Possibilities as mere possibilities 'exist' (the possibility that John may not return exists). ${ }^{8}$ By contrast, merely possible cases do not 'exist'. If they have the status of existing (that is, if they 'present themselves'), then they are not merely possible situations, but actual ones.'

Cases thus are fully specific situations and as such distinct from events, states, facts, and possibilities. In their role as epistemic future alternatives they may moreover come with their own case-specific existence predicate.

\subsection{Cases as exact truthmakers}

Case-NPs such as (4a) quantify over situations that are truthmakers of the caseclause. More precisely, they quantify over exact truthmakers of the case-clause, namely, in (4a), situations in which exactly one student passed the exam and nothing else happened, which means situations wholly relevant for the truth of the sentence a student passed the exam. They will not quantify over sums of such situations or larger situations which make the case-clause true but include other things that are

7 Eintreten excludes epistemically possible situations of the present or the past:

(i) a. ??? Der Fall, dass $n$ eine Primzahl ist, kann eintreten/ist eingetreten.

'The case that $n$ is a prime number could enter/has entered.'

b. ??? Der Fall, dass Hans das Licht angelassen hat, ist eingetreten.

'The case that John has left the light on has entered.'

8 Possibilities thus are best considered entities abstracted from a modal propositional content, just as nonworldly facts may be viewed as entities abstracted from a true propositional content (Moltmann 2013a, Chap. 6).

9 Cases also differ from states of affairs: states of affairs 'exist' whether or not they 'obtain'. States of affairs accept two different existence predicates, exist and obtain, conveying two different modes of being, quite unlike cases. 
not relevant for its truth. Likewise, sentences like (4b) and $(5 a, b)$ refer to exact truthmakers of the case-clause.

Fine's relation of exact truthmaking $\Vdash$ is the relation that holds between a situation $s$ and a sentence $S$ just in case the existence of $s$ necessarily entails the truth of S and s is wholly relevant for the truth of S (Fine 2017). If $s$ is an exact truthmaker of a sentence $S$, then a larger situation properly including $s$ need no longer be an exact truthmaker of S, namely if that situation involves 'information' not relevant for the truth of $\mathrm{S}$.

The notion of an exact truthmaker is similar to, yet distinct from that of a minimal situation supporting a sentence (Kratzer 2002, 2014). There are two important reasons for using the notion of an exact truthmaker rather than that of a minimal truthmaker (Fine 2017). First, there are sentences that have exact verifiers, but lack minimal verifiers (e.g. there are infinitely many prime numbers). ${ }^{10}$ Second, a sentence such as it is windy or it is rainy and windy has two exact verifiers, a situation in which it is (just) windy and a situation in which it is (just) windy and rainy, but it would have only one minimal verifier (a situation in which it is windy). ${ }^{11}$ Case-constructions clearly involve exact verifiers, rather than minimal verifiers. Thus, the first sort of sentence does not prevent case-constructions from applying (the case in which there are infinitely many prime numbers). The second sentence permits reference to a plurality of two cases (the two cases in which it is windy or it is rainy and windy), which should be excluded if cases were minimal truthmakers. $^{12}$

\subsection{The actuality condition on the noun case}

Case-NPs as in (4a) range over actual situations only and not merely possible ones, and so for the plurality of situations that (4b) refers to. I will call this the Actuality Condition. Where does this condition come from? The Actuality Condition cannot come from the truthmaking relation itself since the truthmaking relation, in truthmaker semantics, is a relation that holds between actual as well as possible (and impossible) situations and sentences. Moreover, it could not be a general condition on quantification or reference. Natural language does permit quantification over and reference to non-actual entities, explicitly with NPs such as the success we could have achieved or every letter John needs to write, but also implicitly with

\footnotetext{
${ }_{10}$ See also Kratzer $(2002,2014)$ and Yablo (to appear) for discussion.

11 The NP the two cases in which it is windy or it is windy and rainy may not sound that good. But this can be traced to conditions on the individuation of situations, which, like all entities, should generally not overlap if they are to be countable. This would be a condition imposed by the count noun case, rather than the truthmaking relation itself.

12 The notion of an exact truthmaker has a range of further application, for example the semantics of adverbials (Moltmann 2007) and intensional definite descriptions (the book John needs to write, cf. Moltmann 2013a, Chap. 5, to appear b). It is to be expected that it applies to all the semantic phenomena for which situations have been invoked, including restrictions of the domain of quantifiers and definite NPs and perception reports.
} 
conditionals and modals quantifying over non-actual worlds or situations. ${ }^{13}$ The Actuality Condition rather is a general presupposition of what I call 'ordinary argument positions' of natural language predicates, argument positions that with non-actual entities would result in a sentence that is neither true nor false. Ordinary argument positions are, for example, the argument positions of sortal nouns (building, person, woman). Non-ordinary argument positions include the object argument positions of intensional and intentional transitive verbs (need, look for mention, think about) (which allow for truth with non-actual entities as arguments) and the subject position of existence predicates (which allow for falsehood with non-actual entities as arguments) (Priest 2005, pp. 59-60; Moltmann 2013b, 2015c). ${ }^{14}$ For one-place predicates, the Actuality Condition is given below, where $\mathrm{D}(\mathrm{c})$ is the domain of entities considered actual in the context $\mathrm{c}$ :

(7) The Actuality Condition on ordinary (one-place) predicates

For an ordinary one-place predicate $\mathrm{P}$ and a context $\mathrm{c}$, if for an entity $\mathrm{d}$, $\mathrm{d} \in[\mathrm{P}]^{\mathrm{c}}$ or $\mathrm{d} \in[\text { not } \mathrm{P}]^{\mathrm{c}}$, then $\mathrm{d} \in \mathrm{D}(\mathrm{c})$.

The Actuality Condition also concerns situations once situations are considered part of the domain of entities and potential arguments of predicates. The Actually Condition then applies to the noun case, requiring that its arguments (situations) be in the domain $\mathrm{D}(\mathrm{c})$ of entities considered actual in the context $\mathrm{c}$.

The Actuality Condition can be fulfilled also if the context is not that of the utterance, but the shifted context of a reported propositional attitude or epistemic state (due to the presence of an attitude verb or modal expression). Such a context shift may even be triggered by an adjectival modifier of case (possible/improbablel unlikely/hypothetical case) (cf. Sect. 4.2).

\subsection{Reference to kinds of cases}

Case-NPs as in (4) and (5) stand for particular cases and need to be distinguished from singular definite descriptions that stand for kinds of cases, such as the following:

(7) a. the case in which a student passes the exam

b. the case in which it is rainy on a Sunday

Generic case descriptions as in $(7 \mathrm{a}, \mathrm{b})$ are kind terms in the sense of Carlson $(1977 \mathrm{a}, \mathrm{b})$. Even though they are not of the form of bare plurals or mass nouns, they are semantically on a par with bare mass nouns such as gold and bare plurals such as giraffes when used as kind terms. Thus, generic case descriptions allow for the application of typical kind predicates as in (8a), and they exhibit an existential

\footnotetext{
13 See Priest (2005) and Moltmann (2013b, 2015c), as well as other Meinongians for the defense of the view that quantification and reference are neutral as regards existence and nonexistence.

14 Priest (2005) is not specific as to what predicates are subject to the condition. In Moltmann (2015c), I take existence predicates as well as intentional and intensional predicates (with respect to the relevant argument positions) to be exempt from the condition.
} 
reading with episodic predicates as in $(8 \mathrm{~b})$, which is also characteristic of bare mass nouns and plurals when acting as kind terms (Carlson 1977a, b) ${ }^{15}$ :

(8) a. The case in which someone passes the exam has never occurred before.

b. I have never encountered the case in which a candidate was unable to speak during the oral exam.

Unlike case descriptions, fact descriptions of the sort the fact that $\mathrm{S}$ are never kind terms allowing for kind predicates as in $(8 \mathrm{a}, \mathrm{b})$. The fact that a student passes the exam and the fact that it is rainy on a Sunday stand for single quantificational facts, not a kind whose instances are particular facts involving particular individuals or days.

Case-NPs with disjunctive case-clauses may also stand for pluralities of kinds of cases as in (9a), though the same case-clause may give rise to a single kind of case as in (9b):

(9) a. the two cases in which someone arrives late or someone cannot come

b. the case in which someone arrives late or someone cannot come

(9a) refers to the plurality of the two kinds of cases in (10a), whereas (9b) refers to the kind of case in (10b):

(10) a. $\mathrm{k}([$ someone arrives late $]), \mathrm{k}([$ someone cannot come $])$

b. $\mathrm{k}([$ someone arrives late or someone cannot come $])$

The two interpretations of the disjunctive case-clause in turn will have to be based on two distinct kind-indexed syntactic structures, namely [someone arrives late $]_{\mathrm{k}}$ or $[\text { someone cannot come }]_{\mathrm{k}}$ and [in which someone arrives late or someone cannot come $]_{\mathrm{k}}$. I will turn to that shortly.

\section{Outline of truthmaker semantics}

\subsection{Basics of truthmaker semantics}

The following gives an outline of truthmaker semantics for the present purpose of the semantics of case-constructions. Truthmaker semantics involves a domain of situations containing actual, possible as well as impossible situations. This domain is ordered by a part relation and is closed under fusion. The following standard

\footnotetext{
15 Note that the noun case also allows for kind reference with the bare plurals:

(i) Cases in which someone passes the exam are rare.
}

For some reason, kind predicates like rare or unusual are better in German than in English with definite NPs standing for kinds of cases:

(ii) Der Fall, in dem ein Student das Examen schafft, ist selten/ungewöhnlich. 'The case in which a student passes the exam is rare/unusual.' 
conditions on the truthmaking of sentences with conjunctions, disjunctions, and existential quantification then hold (Fine 2012, 2014, 2017) ${ }^{16}$ :

(11) a. $\quad s \Vdash S$ and $S^{\prime}$ iff for some $s^{\prime}$ and $s^{\prime \prime}, s=\operatorname{sum}\left(\left\{s^{\prime}, s^{\prime \prime}\right\}\right)$ and $s^{\prime} \Vdash S$ and $s^{\prime \prime} \Vdash S^{\prime}$.

b. $\mathrm{s} \Vdash \mathrm{S}$ or $\mathrm{S}^{\prime}$ iff $\mathrm{s} \Vdash \mathrm{S}$ or $\mathrm{s} \Vdash \mathrm{S}^{\prime}$.

c. $\mathrm{s} \Vdash \exists \mathrm{x} S$ iff $\mathrm{s} \Vdash \mathrm{S}[\mathrm{x} / \mathrm{d}]$ for some entity $\mathrm{d}$.

As in Fine (2017), I take the truthmaking conditions for disjunction to be exclusive, which means disjunctions won't have as truthmakers sums of situations that are truthmakers of the disjuncts. Plural case-NPs with disjunctive case-clauses reflect that in the choice of a numeral modifier:

(12) a. the two cases in which Mary received an invitation or John received one

b. ??? the three cases in which Mary received an invitation or John received one

The unacceptability of three in (12b) if both Mary and John received an invitation that a sum of a situation in which Mary received an invitation and a situation in which John received an invitation won't count as a truthmaker of the disjunctive case-clause.

Truthmaking conditions for negative sentences are a matter of controversy. Negative sentences are generally considered a challenge to the truthmaking idea since it is not obvious what sort of entity there is in the world that could make the sentence John did not show up or no one is satisfied true. On some views of truthmaking, negative sentences do have truthmakers; on others, they don't. ${ }^{17}$ The semantics of case-NPs itself bears on the issue. Negative case-clauses generally do not pose an obstacle for the referentiality of definite case descriptions, including of the generic sort:

(13) a. We discussed the case in which John does not show up.

b. The case in which no one is satisfied is not a good prospect.

c. The cases in which either John did not show up or he did not pay attention are numerous.

Clearly, case-constructions require a notion of truthmaking that assigns truthmakers to negative sentences. Fine's $(2012,2014,2017)$ truthmaker semantics accomplishes that by assigning sentences not only truthmakers or verifiers, but also falsifiers. This allows a straightforward formulation of the truthmaking conditions of negative sentences: a truthmaker for $\neg \mathrm{S}$ is a falsifier for $\mathrm{S}$. With $\neg$ as the relation of (exact) falsification, the condition is given below:

\footnotetext{
16 The truthmaking condition for sentences with universal quantification and conditionals are less obvious and in fact controversial. I will not give truthmaking conditions for them here since they won't be specifically relevant for the semantics of case-constructions. See Armstrong (2004) and Fine (2017) for discussion and somewhat similar proposals concerning universal quantification.

17 See Mulligan et al. (1984) and Armstrong (1997, 2004) for discussion.
} 
(14) $\mathrm{s} \Vdash$ not $\mathrm{S}$ iff $\mathrm{s} \dashv \mathrm{S}$

Also complex sentences (conjunctions, disjunctions, existential quantification) are assigned both truthmaking and falsemaking conditions (Fine 2017). A sentence $\mathrm{S}$ then has as its meaning a pair $<\operatorname{pos}(\mathrm{S}), \operatorname{neg}(\mathrm{S})>$ consisting of a positive denotation, the set $\operatorname{pos}(\mathrm{S})$ of verifiers of $\mathrm{S}$, and a negative denotation, the set neg(S) of falsifiers of $\mathrm{S}$.

In this paper, I will disregard negation and focus entirely on non-negated sentences. Given that, it will suffice to make use only of the positive denotation of sentences, which will simply be given as '[S]' for a sentence $S$.

\subsection{Extensions of truthmaker semantics}

\subsubsection{Kinds of situations as truthmakers}

For the purpose of the semantics of case-constructions, Fine's truthmaker semantics needs to be extended so as to allow kinds of situations to be truthmakers (the referents of kind-referring case-NPs). Kinds of situations as truthmakers are involved in examples such as (9a) as opposed to (9b), repeated below:

(15) a. the two cases in which someone arrives late or someone does not come

b. the case in which someone arrives late or someone does not come

In (15a), the two kinds of cases, the case in which someone arrives late and the case in which someone cannot come, act as the truthmakers of the complex caseclause and together form the plural referent of the entire NP. (15b), by contrast, refers to a single kind whose instances are the situations that are the truthmakers of the disjunctive case-clause.

Kinds of cases are considered entities sui generis, but which are strictly individuated by their instances. First, the identity of kinds of cases strictly depends on their instances, as below, where I is the relation of instantiation:

(16) For any two kinds $\mathrm{k}$ and $\mathrm{k}^{\prime}$ of truthmakers, $\mathrm{k}=\mathrm{k}^{\prime}$ iff for all s, s I k $\leftrightarrow \mathrm{s} \mathrm{I} \mathrm{k}^{\prime}$.

Just as any bare plural or mass noun defines as a kind as its referent, every sentence defines a kind whose instances are the sentence's truthmakers:

(17) For any sentence $S$, there is a kind of truthmakers of $S, \mathrm{k}(\mathrm{S})$, such that for every situation $s, \mathrm{~s} I \mathrm{k}(\mathrm{S})$ iff $\mathrm{s} \Vdash \mathrm{S}$.

Like kinds in general (referents of bare plurals and mass nouns), kinds of cases inherit properties from their instances. In the present context, this concerns mainly the truthmaking relation, in the following way: A kind $\mathrm{k}(\mathrm{S})$ of truthmakers of a sentences $S$ will be a truthmakers of $S_{k}$, that is, $S$ bearing a kind index $k$ : 
(18) Truthmaking with kinds of truthmakers

For a sentence $S, \mathrm{k}(\mathrm{S}) \Vdash \mathrm{S}_{\mathrm{k}}$.

Based on kind-indexing, a sentence will then have a kind-based denotation as below:

(19) The kind-based positive denotation of sentences

For a sentence $S,\left[S_{k}\right]=\{k(S)\}$

Of course, $\{k(S)\}$ is also just the set $\left\{\mathrm{s} \mid \mathrm{s} \Vdash \mathrm{S}_{\mathrm{k}}\right\}$ of truthmakers of $\mathrm{S}_{\mathrm{k}}$.

For a disjunction $S_{k}$ or $S_{k}^{\prime}$ (as for the example (15a)), the ordinary denotation will be a set of kinds of truthmakers (of the disjuncts):

$\left[\mathrm{S}_{\mathrm{k}}\right.$ or $\left.\mathrm{S}_{\mathrm{k}}^{\prime}\right]=\left\{\mathrm{k}(\mathrm{S}), \mathrm{k}\left(\mathrm{S}^{\prime}\right)\right\}$

The number of kind-based meanings will of course increase with the complexity of the sentence.

Kind-based meanings permit reformulating standard alternative semantics in terms of truthmaker semantics if kinds of situations are identified with propositions. In alternative semantics, questions are assigned as meanings sets of propositions that are their possible answers. Question meanings can now be taken to sets of kinds of situations. Thus, a alternative question (which I return to in the context of caseanaphora in Sect. 6) will be assigned as its meaning the set of kinds of situations that are truthmakers of the disjuncts, so that (20) will also be the meaning of (21):

(21) Did someone arrive late or did someone not come?

Kind-based meanings thus will serve different semantic purposes, being involved in the semantics of case-NPs as well as that of disjunctive questions.

\subsubsection{Extensions of truthmaker semantics}

Truthmaker semantics as outlined in the previous section needs to be supplemented by an account of context dependency. I will make use of a notion of context that serves strictly the purposes of this paper, setting aside all other linguistic issues of context dependency. This notion is a local, shiftable context, which can be taken to be either the utterance of the sentence itself or else a reported attitude or epistemic state, for a sentence embedded under an attitude verb or epistemic modal. ${ }^{18}$ Such a context, being a local context, may shift for the evaluation of an embedded sentence in the scope of an attitude verb or modal expression. The context for the evaluation of the entire sentence is the primary context and the shifted context for the evaluation of an embedded sentence a secondary context. A context $\mathrm{c}$ will be associated with a

\footnotetext{
18 Such contexts can be taken to consist in attitudinal objects, in the sense of Moltmann (2013a, 2014, 2017a), which include claims, requests, beliefs, inquiries, and considerations. See also Fn 20.
} 
domain $\mathrm{D}(\mathrm{c})$, which consists in entities considered actual by the agent(s) associated with c. A sentence then denotes a set of situations (its exact truthmakers) only relative to a context $\mathrm{c}$. A simple sentence such as The president is responsible then has a (positive) meaning relative to a context $\mathrm{c}$ that consists in the set of situations attributing responsibility to the president in $\mathrm{D}(\mathrm{c}) .{ }^{19}$

Another extension of truthmaker semantics consists in the application of the truthmaking relation $\Vdash$ to situations and epistemic states, such as beliefs, judgments, inquiries, and considerations. ${ }^{20}$ The belief that John left has as truthmakers situations in which John left that are prior to that belief. Moreover, the belief that John won the race or Mary did has two types of truthmakers: the kind of situation in which John won the race and the kind of situation in which Mary won the race. These are the very same situations that resolve a state of uncertainty or an inquiry whether John won the race or Mary did. Beliefs with disjunctive contents may thus share their truthmakers with corresponding states of uncertainty or acts of inquiry.

\section{The semantics of case-nominals with clausal modifiers: preliminary version}

Based on the notion of truthmaking, the semantics of case-nominals describing particular cases can, in a preliminary version, be given as follows:

(22) The semantics of case-nominals describing particular cases (preliminary version)

For a context $\mathrm{c},[\text { case in which } \mathrm{S}]^{\mathrm{c}}=\left\{\mathrm{s} \mid \mathrm{s} \in[\text { case }]^{\mathrm{c}} \& \mathrm{~s} \in[\mathrm{S}]^{\mathrm{c}}\right\}$

Here case is taken to have simply the meaning of 'situation', though this will be modified in the next section.

The semantics of case-nominals describing kinds of cases, similarly, will be as in (23a), where case $_{\text {kind }}$ has the meaning in (23b) derived from that of case (again with a meaning that will be modified shortly):

(23) a. The semantics of case-nominals describing kinds of cases (preliminary version)

For a context $\mathrm{c},\left[\text { case }_{\text {kind }} \text { in which } \mathrm{S}_{\mathrm{k}}\right]^{\mathrm{c}}=\left\{\mathrm{k} \mid \mathrm{k} \in\left[\text { case }_{\text {kind }}\right]^{\mathrm{c}} \& \mathrm{k} \in\left[\mathrm{S}_{\mathrm{k}}\right]^{\mathrm{c}}\right\}$

b. For a context $\mathrm{c}$ and kind $\mathrm{k}$ of situations, $\mathrm{k} \in\left[\text { case }_{\mathrm{kind}}\right]^{\mathrm{c}}$ iff for all $\mathrm{s}$, if $\mathrm{s} \mathrm{I} \mathrm{k}$, then $\mathrm{s} \in[\text { case }]^{\mathrm{c}}$.

\footnotetext{
19 Such sentence meanings can be obtained compositionally, for example if is responsible is assigned a denotation [is responsible $]^{\mathrm{c}}$ relative to a context $c$ that is a function mapping an individual $d$ to the set of situations $s$ in which $d$ is responsible. The meaning of The president is responsible is then obtained by function application: [The president is responsible $]^{\mathrm{c}}=[\text { is responsible }]^{\mathrm{c}}\left([\text { the president }]^{\mathrm{c}}\right)$. In this paper, to keep things simple, I take one-place predicates to denote sets of entities (relative to a context).

20 In Moltmann (2013a, 2014, 2017a), I take epistemic states to belong to the more general category of attitudinal objects, which includes desires, claims, decisions, and requests. Attitudinal objects, most importantly, have a content consisting of truthmaking or satisfaction conditions, yet they share the particularity and concreteness of events.
} 
Here only the case-clause needs to bear a kind index in order to denote a set of kinds of truthmakers, as required by the semantics of the case-nominal.

In (22) and (23), the semantic contribution of the clause in which $\mathrm{S}$ is treated as that of an intersective modifier of the noun case, denoting the set of truthmakers of $\mathrm{S}$, the meaning it shares with $\mathrm{S}$ (or that $\mathrm{S}$ ). The contribution of the preposition is thus ignored. There is support for that analysis and that is that in some languages other than English, for example German, case-clauses may be formed without a preposition, with what corresponds to a that-clauses rather than an in whichclause $^{21}$ :

(24) der Fall, dass jemand zu spät kommt

'the case that someone is late'

It is customary to think that that-clauses and in which-clauses differ in that the latter but not the former are relative clauses. But it is not universally accepted. Thus, Kayne (2010) argues that that-clauses are also relative clauses, a view which support an analysis of clauses as in (24) as intersective modifiers. ${ }^{22}$

The question remains what semantic contribution the preposition in could have in in which-clauses. Two observations bear on the issue. First, in general in can relate a clausal content to a situation even if that situation is an exact truthmaker of the clause, as in the situation in which a student is late. This means in can relate a situation to itself. Second, where can be used in place of in which (the cases where a student was late). This indicates that in has in fact a locative meaning which includes self-containment of a situation. The semantics of the construction case in which $\mathrm{S}$ (for particular cases) should then be $\left\{\mathrm{s} \mid \exists \mathrm{s}^{\prime}\left(\mathrm{s} \in[\text { case }]^{\mathrm{c}} \&<\mathrm{S}^{\prime}, \mathrm{s}>\in[i n]^{\mathrm{c}}\right.\right.$ $\left.\left.\& s^{\prime} \in[S]^{c}\right)\right\}$, where pragmatic conditions are to ensure that in is restricted to conveying self-containment.

\section{The case space requirement}

The semantics of case-nominals given so far requires an important modification: a situation or kind of situation can be a case only within a case space, a set of at least two alternatives. This Case Space Requirement, as I will call it, is part of the lexical

\footnotetext{
${ }^{21}$ Definite case-NPs in German thus look like English definite NPs with fact, possibility, idea, proof etc. as head, which select that-clauses rather than in which-clauses.

22 Note that with other determiners than the definite one, German switches to in which-clauses:

(i) a. ein Fall, in dem/* dass es regnet 'a case in which/that it rains'

b. mehrere Fälle, in denen es regnete 'several cases in which it rained'
}

This indicates that that-clauses are syntactically selected by certain nouns and in addition need to be licensed by the definite determiner, whereas in which-clauses appear when those two conditions are not fulfilled. The alternation between that-clauses and in which-clauses thus is a syntactic one and not indicative of a semantic difference. 
meaning of the noun case. The Case Space Requirement is of particular theoretical interest in that it connects truthmaker semantics to alternative semantics.

The Case Space Requirement is reflected in the semantics of all types of caseconstructions: case-NPs with clausal modifiers, case-anaphora, and the predicate is the case, as we will see. Case spaces may be determined in two distinct ways: by a case-clause (sentential case spaces) or by an epistemic state of uncertainty (epistemic case spaces).

\subsection{Sentential case spaces}

The Case Space Requirement manifests itself first of all in that sentences cannot be used for case reference that have as truthmakers single known facts in the past or present or single time-less facts:

(25) a. ??? We discussed the case in which John returned yesterday.

b. ??? The case in which John has solved the problem was unexpected.

c. ??? The case in which it is raining outside bothers us.

d. ??? The case in which 3 is a prime number is well known.

The unacceptability of such examples contrasts with the acceptability of the corresponding sentences with fact descriptions:

(26) a. We discussed the fact that John returned yesterday.

b. The fact that John has solved the problem was unexpected.

c. The fact that it is raining outside bothers us.

d. The fact that 3 is a prime number is well known.

It also contrasts with the acceptability of case-NPs with existentially quantified or disjunctive case-clauses, as in $(4 \mathrm{a}, \mathrm{b})$ and $(5 \mathrm{a}, \mathrm{b})$, which involve more than one case as semantic value. Cases are not just isolated actual situations, but rather situations within a space of alternatives.

There are other ways in which the Case Space Requirement may be satisfied by a case-description than by an existentially quantified or disjunctive case-clause. First, the Case Space Requirement may be satisfied by a case-clause that is true at different times and thus has different time-related truthmakers ${ }^{23}$ :

(27) the cases in which John won the race

Also a definite NP in the case-clause may lead to a case space, namely if it has different referents at different times or places:

\footnotetext{
${ }^{23}$ The same case-clause can modify a case-NP standing for a kind whose instances are truthmaking situations at different times, as in (i):
}

(i) The case in which John won the race has occurred only twice. 
(28) a. the cases in which the president was a democrat

b. the cases (over the years) in which the number of students was less than 1000

(29) a. the cases in which the head of state is a king

b. the cases (in this country) in which the number of students is less than 1000

Another way to meet the Case Space Requirement is for the case-clause to describe a part of a mathematical case distinction, involving variables in a mathematical extension of English:

(30) the cases in which $n$ is a prime number

The Case Space Requirement is not a requirement that a case-NP refer to a plurality of particular cases. The requirement may also be satisfied if the case-NP refers to a single particular case within a set of alternatives that is determined by the case-clause.

One such construction by which this is possible is modification of the case-NP by ordinal or superlative adjectives:

(31) a. the first case in which a student failed the exam

b. the worst case in which the two people had a dispute

Here the adjectival modifier relates to an order on a set of alternative situations making the case-clause true, and it ensures that the case-NP refers to a unique element in that set.

Another way for a case-NP to refer to a single case among a set of alternatives involves contrastive focusing of a constituent of the case-clause:

(32) a. The case in which Jérry won the race was totally unexpected.

b. I recall the case in which John was éager to do his homework.

Contrastive focusing goes along with a set of alternatives relevant in the context of the utterance (Rooth 1992). Specifically, given the present context, contrastive focusing sets up alternative situations involving contextually relevant semantic values other than the semantic value of the focused constituent. In (32a), these are situations in which a relevant person other than Jerry won the race. In (32b), these are situations in which John was something other than eager to do his homework. These situations together with the situation referred to make up the case space.

A case space induced by focusing is also involved in the semantics of case-NPs with only as modifier, a modifier that associates with focus:

(33) Mary remembered the only case in which Jérry won the race.

Here the case space consists in different situations of someone winning the race among which there will be just one, involving Jerry, for only to select. 
Contrastive focus and expressions associating with focus have been among the main motivations for alternative semantics, a semantic approach on which a sentence has as semantic value a set of propositions or alternatives, rather than a single proposition. Thus, Rooth (1992) assigns a focused sentence a focus-semantic value, the set of contextually relevant propositions that are obtained by replacing the semantic value of the focused constituent by other semantic values. The ordinary semantic value of the sentence will be a proposition, and the sentence presupposes that that proposition is part of the focus-semantic value.

Alternative semantics has also been applied to questions, which have been assigned as their semantic value the set of true and false answers (Hamblin 1973), to disjunctions, which have been assigned as their semantic value the sets of the propositions expressed by the disjuncts (Aloni 2007), to conditionals (Santorio 2018), and to certain types of indefinites (Kratzer and Shimoyama 2002).

There is a significant connection between truthmaker semantics and alternative semantics. Truthmaker semantics, in a way, provides a version of alternative semantics, namely on which the alternatives are not propositions, but truthmaking situations. Truthmaker semantics assigns sets of (possibly different) truthmaking situations to disjunctions and to existentially quantified sentences, rather than sets of propositions. Truthmaker semantics can be reformulated, though, so as to assign kinds of truthmakers to disjuncts, the correlates of propositions (and for certain purposes it needs to be so reformulated, such as for the semantics of case-NPs standing for pluralities of kinds of cases).

Deviating somewhat from Rooth, I will not assign the very same sentence $S$ containing a focused constituent two different semantic values, but rather distinguish two syntactic structures for $S$ : a syntactic structure without focus structure and a syntactic structure with focus structure. Truthmakers of $S$ without its focus structure will be the ordinary truthmakers of $S$. Truthmakers of $S$ with its focus structure, $\mathrm{S}\left[\mathrm{Y}_{\text {focus }}\right]$, will also include truthmakers of the result of replacing the focused constituent $\mathrm{Y}$ by a different expression $\mathrm{X}$ (relevant in the context $\mathrm{c}$ ), where $\mathrm{X}$ is of the same syntactic category as $\mathrm{Y}\left(\mathrm{X} \in \mathrm{CAT}_{\mathrm{Y}, \mathrm{c}}\right)$ :

(34) Truthmaking for sentences with focus structure

For a context $\mathrm{c}$ and a situation $\mathrm{s}, \mathrm{s} \Vdash \mathrm{S}\left[\mathrm{Y}_{\text {focus }}\right]^{\mathrm{c}}$ iff $\exists \mathrm{X}\left(\mathrm{X} \in \mathrm{CAT}_{\mathrm{Y}, \mathrm{c}} \&\right.$ $\left.\mathrm{s} \Vdash \mathrm{S}[\mathrm{X} / \mathrm{Y}]^{\mathrm{c}}\right)$

Truthmaker Semantics for the present purposes has a significant advantage over standard alternative semantics since it allows case-NPs to make reference to a plurality of cases as well as reference to a single case within a background of alternatives. A unified semantics of case-NPs would not be available on the standard, propositions-based version of alternative semantics, which does not allow for reference to particular cases.

Truthmaker semantics extended to kinds as truthmakers will allow for sets of kinds of cases as case spaces, for examples such as this:

(35) the case in which an Américan wins the race 
In (35) the case space will consist in kinds of the sort 'the case in which an American wins the race', 'the case in which a Frenchman wins the race', 'the case in which a German wins the race' etc.

Semantically, the involvement of a case space means that the noun case does not just take a particular situation or kind of situation as an argument, but also a set of alternative situations or kinds of situations, a case space. The case space must include the situation argument of case and have at least two elements. In the examples discussed in this section, the case space is determined by a sentence, the case-clause (possibly together with its focused structure), as the set of truthmakers or kinds of truthmakers of that sentence:

(36) Definition of a sentential case space

For a sentence $S, C S(S)=\left\{s \mid s \Vdash S \& \exists s^{\prime}\left(s^{\prime} \Vdash S \& s \neq s^{\prime}\right)\right\}$.

A sentential case space will be based on a syntactic (indexing) relation between the noun case and the case-clause as in (37a) or for a case-clause with focusing as in (37b):

(37) a. For a context $\mathrm{c},\left[\text { the } \text { case }_{\mathrm{i}} \text { in which } \mathrm{S}_{\mathrm{i}}\right]^{\mathrm{c}}=$ the $\mathrm{s}\left[<\mathrm{s}, \mathrm{CS}(\mathrm{S})>\in\left[\right.\right.$ case $^{\mathrm{c}}$ $\left.\& s \in S^{c}\right]$

b. For a context $c$, [the case $_{\mathrm{i}}$ in which $\left.\mathrm{S}\left[\mathrm{Y}_{\text {focus }}\right]_{\mathrm{i}}\right]^{\mathrm{c}}=$ the $\mathrm{s}\left[<\mathrm{s}, \mathrm{CS}\left(\mathrm{S}\left[\mathrm{Y}_{\text {focus }}\right]\right)>\right.$ $\left.\in[\text { case }]^{\mathrm{c}} \& \mathrm{~s} \in \mathrm{S}^{\mathrm{c}}\right]$

The semantic contribution of focus in the case-clause will just be that of determining the case space.

\subsection{Epistemic case spaces}

Besides being determined by a sentence, a case space may also be determined by an epistemic state. Such an epistemic case space consists of alternatives supported by an epistemic state of uncertainty associated with the utterance of case-construction. This epistemic state may be indicated by an epistemic modal of possibility, as in (38a), or understood implicitly, as in (38b), when the case referred to is not a known fact, but considered a possibility. (38a, b) contrast with (38c), where the case-NP refers to an actual particular case ${ }^{24}$ :

\footnotetext{
24 Some speakers do not accept the modal in (38a). Those speakers appear to also not accept the modal might below, where it does not contribute to the propositional content either:
}

(i) the possibility that John might not return

This particular 'harmonic' use of the modal can be found in other languages as well, for example German, where both (iia) and (iib) are acceptable:

(ii) a. der Fall, dass Hans nicht zurückkommen könnte 'the case in which John might not return'

b. die Möglichkeit, dass Hans nicht zurückkommen könnte 'the possibility that John might not return' 
(38) a. We cannot exclude the case in which John might have returned yesterday.

b. We cannot exclude the case in which John returned yesterday.

c. ??? The case in which John returned yesterday surprised us.

The contrast below makes the same point:

(39) a. The case in which it might be raining outside needs to be taken into consideration.

b. ??? The case in which it is raining outside bothers us.

The case-NP in (39a) unlike that in (39b) does not describe an actual situation, but rather one epistemic possibility besides others.

In $(38 \mathrm{a}, \mathrm{b})$, the case space consists in the (kinds of) situations that are truthmakers of the epistemic state of uncertainty indicated by the (explicit or implicit) epistemic modal:

(40) Definition of an epistemic case space

For an epistemic state $d, \mathrm{CS}(\mathrm{d})=\left\{\mathrm{s} \mid \mathrm{s} \Vdash \mathrm{d} \& \exists \mathrm{s}^{\prime}\left(\mathrm{s}^{\prime} \Vdash \mathrm{d} \& \mathrm{~s} \neq \mathrm{s}^{\prime}\right)\right\}$.

By contrast, in the case of a sentential case space, the case space consists of (kinds of) situations that are truthmakers of a sentence. The noun case is thus subject to the general condition below:

(41) Lexical condition on the noun case

For a context $c$, a situation $s$ and a set $X$, if $\left\langle s, X>\in[\text { case }]^{\mathrm{c}}\right.$, then for an epistemic state or sentence $d, \mathrm{X}=\mathrm{CS}(\mathrm{d})$ and $\mathrm{s} \in \mathrm{X}$.

In $(38 \mathrm{a}, \mathrm{b})$ and $(39 \mathrm{a})$, the modal does not contribute to the propositional content of the case-clause, since the case-NP refers not to a situation of a possibility obtaining, but to one possible situation among others that are being considered. The contribution of the epistemic modal is just to indicate the epistemic state of uncertainty that goes along with maintaining the content of the case-clause and thus is that of a mere 'force indicator' (Papafragou 2006). ${ }^{25}$

Besides being indicative of an epistemic state, the (explicit or implicit) modal in case-NPs ensures the satisfaction of the Actuality Condition, by shifting the context of evaluation for case. The Actuality Condition will then be fulfilled with respect to a domain of objects associated with the state of uncertainty rather than that of the utterance context. This raises, however, a question for compositional semantics, namely how can the Actuality Condition be fulfilled that way, given that the noun case is not in the scope of the modal which introduces the secondary context? The answer can be found in an important syntactic view about relative clauses, namely according to which the head noun of a relative-clause construction (case in case in which $\mathrm{S}$ ) has a representation inside the relative clause, related to the head noun in

\footnotetext{
25 In fact, for those speakers that accept an overt modal, the very same semantic effect can be achieved using sentence adverbials:
}

(i) the case in which John has perhaps/possibly already returned 
its upper position either by movement (Vergnaud 1974; Kayne 1994; Carlson 1977a, b; Cinque 2015) or by matching (Chomsky 1965; Cinque 2015). ${ }^{26}$ Making use of the former account means that (42a) can have as input to semantic interpretation the syntactic representation in (42b) with reconstruction of the noun case into the lower position and the in which-clause in its original adverbial position.

The denotation of (42a) will then be as in (42c), which involves a shift of the local context to that of an epistemic state e, which is considered an argument of might ${ }^{27}$ :

(42) a. the case in which John might return

b. the $\mathrm{t}_{\mathrm{i}}$ [ might John [in which case $\mathrm{i}_{\mathrm{i}}$ ] return]

c. [the case in which John might return $]^{\mathrm{c}}=$ the situation s such that $\exists \mathrm{s}^{\prime}\left(<\mathrm{s}^{\prime}, \mathrm{s}>\in[i n]^{\mathrm{e}} \&<\mathrm{s}, \mathrm{CS}(\mathrm{e})>\in[\text { case }]^{\mathrm{e}} \& \mathrm{~s}^{\prime} \in[\mathrm{S}]^{\mathrm{e}}\right)$, for a relevant epistemic state e, such that e $\in[\text { might }]^{\mathrm{c}}$

In (42c), the Actuality Condition is to be satisfied with respect to $\mathrm{D}(\mathrm{e})$ and case takes the case space determined by e as its second argument.

Also descriptions of mathematical uncertainties (at the relevant point in time) can be case-constitutive, with or without overt epistemic modal:

(43) a. The case in which there is a solution to the equation cannot be excluded.

b. The case in which there might be a largest prime number has long been ruled out.

By contrast, sentences describing known mathematical facts cannot set up a case space:

(44) a. ??? The case in which 2 is a prime number is interesting.

b. ??? The case in which there is no largest prime number is well known.

Epistemic case space may also be indicated by adjectival modifiers of case-NPs. Case-NPs are fine with adjectival modifiers indicating epistemic uncertainty, as in (45a), but are less good with those indicating a stronger form of acceptance, as in (45b):

(45) a. in the unlikely/improbable/unforeseeable case in which the treasure is returned

b. ??? in the likely/probable/foreseeable case in which the treasure is returned

\footnotetext{
${ }^{26}$ The motivations for that syntactic view include connectivity effects, such as the antecedent of each other being inside the relative clause below:

(i) the respect for each other ${ }_{i}$ [that [Sue and Mary $]_{i}$ display]

${ }^{27}$ For an elaboration of the view on which modals are predicates of epistemic states or more generally modal objects see Moltmann (2015b, 2017a, 2018a).
} 
Case-NPs exclude factive modifiers:

(46) ??? the fortunate/regrettable case in which Mary returns

The epistemic states indicated in (45a) are clearly associated with a case space, less so the ones indicated in (45b) and certainly not the ones in (46), which exclude alternatives.

Epistemic modal adjectives as in (45a), like epistemic modal verbs, involve a shift of the local context to that of the epistemic state in question. This means that the Actuality Condition is to be satisfied with respect to the domain associated with that epistemic state, not the domain of the primary context.

To summarize, if the case-clause does not set up a case space itself, then a state of uncertainty, indicated by an (explicit or implicit) modal expression, may set up a case space. In that case, the Actuality Condition needs to be satisfied only with respect to the secondary context introduced by the modal, not the primary context (that of the utterance of the entire sentence).

One might try to unify the two sorts of case spaces by taking a case space set up by a sentence to be a special case of an epistemic case space. However, this is implausible for a case-clause with an indefinite as in $(4 a, b)$. Rather two distinct sources for a case space need to be distinguished, one being the case-clause itself, the other an epistemic state of uncertainty. Whereas the former is based on a syntactic relation between case and the case-clause, the latter is tied to the local, secondary context of evaluation.

Case spaces can also be set up by an overt or implicitly understood future tense:

(47) a. The case in which John will return is very unlikely.

b. The case in which John returns tomorrow can be excluded.

Future tense sets up a case space because it represents different options or at least different epistemic possibilities. Future tense is generally considered a modal, which means it would introduce a modal object whose truthmakers make up the case space, on a par with the epistemic state introduced by an epistemic modal.

\section{Case-anaphora with conditionals, disjunctions, and questions}

Case-anaphora give further support for cases as situations in the role of truthmakers within a space of alternatives. The Case Space Requirement can be satisfied with case-anaphora whose antecedent is introduced by an utterance of a different speaker, by a particular visual situation, by conditionals, by disjunctions, by yes/noquestions, and by particular types of attitude reports and modal sentences.

The involvement of a case space manifests itself in the difference it makes whether a case-anaphor relates to a preceding utterance of the same speaker or of a different speaker. The case-anaphor is not very good in the discourse below: 
(48) ??? John won the race. In that case, Mary will be happy.

Here that case should refer to the kind of situation in which John won the race. However, being described by an assertion of the same speaker, this kind of situation does not come with alternatives and thus does not belong to a case space. The Case Space Requirement can be fulfilled, though, when the preceding sentence is asserted by a different speaker:

(49) A: John won the race.

B: In that case, Mary will be happy.

The case-anaphor in B's utterance is acceptable only if B is not yet convinced that John won the race. In that case, the case-anaphor will relate to a weaker attitude than belief, say of B's hypothetical acceptance that John won the race as a reaction to A's assertion. That attitude allows for alternatives and thus sets up a case space.

The Case Space Requirement is also apparent in the absence of an antecedent sentence introducing the case. Compare (50a) and (50b) uttered out of the blue:

(50) a. In that situation, I would flee.

b. In that case, I would flee.

(50a) and (50b) are appropriate in different visual contexts. Whereas (50a) is appropriate when confronted with a single situation, (50b) is acceptable only when pointing at one situation among several that are visually displayed. ${ }^{28}$

Let us then turn to case-anaphora relating to the utterance of a preceding sentence by the same speaker. First, yes/no-questions support case-anaphora, as in the singlespeaker discourse below, in which the speaker decides not to wait for the addressee's answer to the question:

(51) Did John win the race? ... In that case, Mary will be happy.

A yes/no-question is associated with an attitude of inquiry supporting two alternatives and thus sets up a case space, a requirement for the use of a caseanaphor within the same context.

Also disjunctive declarative sentences permit case-anaphora. The reason is that an assertion with a disjunctive content permits as many alternatives as there are disjuncts. As such, it sets up a case space for a case-anaphor applying within the same local context ${ }^{29}$ :

(52) a. John will interview or Mary will. In either case, we should be well prepared.

\footnotetext{
${ }^{28}$ Thanks to a referee for pointing out the source of the potential unacceptability of (50b).

29 Note that the presence of either in (52a) and three in (52b) shows the exclusive semantics of disjunctions just as in the case of case-NPs with disjunctive case-clauses: situations in which John and Mary will interview could not constitute a third case, and similarly for situations, for example, in which the exam is about both Goethe and Schiller.
} 
b. The exam will be about Goethe, Schiller, or Kleist. In all three cases, the same sorts of questions will be asked.

Finally, conditionals support case-anaphora:

(53) a. If it rains, we won't go.

b. In that case/In such a case, we will stay home.

c. Let's better not think about that case.

That case in (53b) and (53c) refers to the kind of situation that is an exact truthmaker of the antecedent of the conditional. The attitude associated with the antecedent of a conditional is that of hypothetical acceptance, not that of belief (Stalnaker 1984). Being a state of hypothetical acceptance permits it to set up a case space, consisting of the kind of situation satisfying the antecedent, but also an alternative kind of situation falsifying the antecedent.

In that case itself forms the antecedent of a conditional, involving reference to the situations that are truthmakers of the antecedent of that case. Note that the noun case can also serve to form non-anaphoric conditionals, as in English in (54a) and the German translation with im Fall in (54b): ${ }^{30,31}$

(54) a. In a case in which it rains, we will have to cancel the garden party.

b. Im Fall, dass es regnet, werden wir das Gartenfest absagen.

There are reasons independent of the occurrence of the noun case for taking truthmaking to be involved in the semantics of conditionals. Thus Fine $(2012,2014)$ argues for a truthmaker-based (as opposed to a possible worlds-based) semantics of counterfactual conditionals. A truthmaker-based account of conditionals in general would be based on the schema below, for a suitable relation $R$ between antecedent and consequent situations ${ }^{32}$ :

(55) If $\mathrm{S}$, then $\mathrm{S}^{\prime}$ is true iff for every situation $\mathrm{s}, \mathrm{s} \Vdash \mathrm{S}$, there is a situation $\mathrm{s}^{\prime}$ such that sRs' and $\mathrm{s}^{\prime} \Vdash \mathrm{S}^{\prime}$.

\footnotetext{
30 In case can also act as a complementizer:

(i) We will take an umbrella in case it rains.
}

Here the main clause is said to be true in view of one possible future course of events, namely in which a situation-like case as described by the case-NP occurs. In English, the construction is grammaticalized, containing no determiner before case and no wh-phrase in which after it $*$ in the case it rains, * incase in which it rains).

31 There are differences between ordinary if-conditionals and case-conditionals. If-conditionals can go along with adverbs of quantification, of which the if-clause appears to act as a restriction, but caseconditionals cannot:

(i) a. If a student fails the exam, he usually tries again.

b. ??? In case a student fails the exam, he usually tries again.

32 See also Kratzer (2014) and references therein for analyses of conditionals on the basis of situations. 
Such a semantics can also be applied to the conditional prepositional phrase in that case:

(56) In that case, $\mathrm{S}$ is true iff for every situation s such that $\mathrm{S} I$ [that case], there is a situation $\mathrm{s}^{\prime}, \mathrm{sRs}^{\prime}$ and $\mathrm{s}^{\prime} \Vdash \mathrm{S}$.

Case-anaphora raise the question of how the Actuality Condition associated with the noun case is satisfied, since case-anaphora generally do not make reference to situations considered actual. Given the semantics in (56), it is satisfied because caseanaphora involve reference to kinds of cases, not particular cases, and kinds of cases always satisfy the Actuality Condition.

Case-anaphora are subject to general constraints on anaphora. In particular, a case-anaphor can refer only to a situation that has been made at least as explicit as its alternatives, as seen in the contrast between simple yes/no questions and disjunctive ones below:

(57) a. Will you come? In that case/??? In either case, I would come too.

b. Will you come or not? In both cases/In either case/??? In that case, I would come too.

Simple yes/no-questions provide a single case for a subsequent case-anaphor, even though they set up a case space with two alternatives. By contrast, corresponding disjunctive questions, which set up the same case space, provide two cases for a subsequent case-anaphor to refer to. ${ }^{33}$

\section{Case-anaphora with attitude verbs and epistemic modals}

The Case Space Requirement manifests itself also with case-anaphora relating to a clause embedded under an attitude verb in a preceding sentence. Such caseanaphora display striking differences in acceptability with respect to choices of different attitude verbs.

First of all, as expected, (non-disjunctive) complement clauses of factive attitude verbs do not support subsequent case-anaphora. This holds for case-anaphora both within the same secondary context as in (58a) and in the primary context as in (58b):

\footnotetext{
${ }^{33}$ Constraints on the linguistic representation of antecedents are familiar from the semantic literature on anaphora, from examples such as:

(i) a. Someone left. He did not come back.

b. ??? Not everyone stayed. He did not come back.
}

Case-anaphora, though, are not expected to fall under the very same constraint as ordinary pronominal anaphora since they refer within a case space and do not have pronominal form. But case-anaphora show contrasts analogous to that in (i):

(ii) a. John believes that Mary will go to the party. In that case, I will go too.

b. ??? John doubts that Mary won't go to the party. In that case, I will go too. 
(58) a. ?? John is happy that he won the election. In that case, he wants to celebrate. b. ?? John noticed that Mary is at home. In that case, Bill is at home too.

Factive attitudes do not set up a case space, neither for the context of the described agent nor the speaker's context. There is one exception to that, of course, and that is when the complement clause itself sets up a case space and the reported attitude thereby supports different alternatives. This is the case for disjunctions as below ${ }^{34}$ :

(59) John knows that he will win or lose. In either case, he will continue training.

Complement clauses of the nonfactive attitude verbs hope and fear do support case-anaphora (within the same secondary context):

(60) John hopes/fears that Mary is at home. In that case, he believes that Bill is at home too.

A hope or fear that $\mathrm{S}$ comes with an uncertainty as to whether $\mathrm{S}$, that is, an epistemic state that supports alternatives to $S$ and thus sets up a case space. A reported hope or fear that $\mathrm{S}$ also supports case-anaphora within the primary context, namely if the speaker himself hypothetically accepts that $S$ :

(61) John hopes/fears that Mary is at home. In that case, I would believe that Bill is at home too.

Fear and hope contrast with believe, which does not support case-anaphora within the same secondary context, as in (62a), but only in the primary context, as in (62b), though not if the agent of the belief is the speaker, as in (62c):

(62) a. ??? John believes that Mary is at home. In that case, he believes that Bill is at home too.

b. John believes that Mary is at home. In that case, I would believe that Bill is at home too.

c. ??? I believe that Mary is at home. In that case, I believe that Bill is at home too.

A belief that $S$ does not support alternatives to $S$ and thus does not set up a case space. (62b) presupposes that the speaker is uncertain as to the truth of John's belief.

Other positive, truth-directed attitudes exhibit the very same pattern as belief, for example assertions:

\footnotetext{
${ }^{34}$ Also focus in a factive complement can support a case-anaphor. Below the case-anaphor is the complement of a predicate expressing an objectual attitude:

(i) John is delighted that Gereon won the election. We were completely unprepared for that case.

Here it is the background attitude of taking different winners into consideration that supports the alternatives in the case space.
} 
(63) a. ??? John claims that Sue won the race. In that case, he wants to celebrate.

b. John claims that Sue won the race. In that case, I will celebrate.

c. ??? I claim that Sue won the race. In that case, I will celebrate.

Assertions do not come with a state of uncertainty that would support alternatives to the reported content. But another agent may adopt that content against the background of a weaker epistemic state, which then sets up a case space for a caseanaphor to relate to.

Attitude verbs such as think, imagine, and dream do not support case-anaphora at all within the secondary context:

(64) a. ?? John thinks that Mary is not interested in him. In that case, he wants to ask Sue out.

b. ?? John imagines that he is rich. In that case, he imagines that he was very generous.

c. ?? John dreamt that he was a bird. In that case, he wanted to fly.

The reason is that attitudes such as thinking (in the sense of 'entertaining'), imagining and dreaming are not epistemic in nature and could thus not be associated with an epistemic state of uncertainty. ${ }^{35}$ They will hence not be able to set up an epistemic case space for a case-anaphor within the same secondary context.

Case spaces can be set up also by epistemic modals. Epistemic modals of possibility and necessity both support case-anaphora, though speakers differ somewhat as to which modals support them better:

(65) a. John might have arrived. In that case, Mary should be relieved.

b. John must be at home. In that case, Mary will be at home too.

The support of case-anaphora with epistemic must presupposes that epistemic must is not factive, a view defended by Karttunen (1972). ${ }^{36}$ Epistemic may and, to an extent, must are indicative of an epistemic state permitting alternatives and thus setting up a case space.

In contrast to epistemic modals, deontic and ability modals do not permit caseanaphora:

(66) a. You may take an apple. ??? In that case, you may take a pear too.

b. ??? You must leave. In that case, your wife will leave too.

c. ?? John can lift the table. In that case, he should carry it upstairs.

35 Disjunctive that-clauses with imagine do not generally improve subsequent case-anaphora:

(i) ?? John imagined that he was a king or a president. In either case, he imagined that he was well liked.

This makes clear that case-anaphora could not involve a sentential case space, but only an epistemic one.

36 However, see Von Fintel and Gillies (2010) for a defense of the factivity of must. 
A case space for the noun case can be set up only by an epistemic state, not an obligation or permission, even if obligations and permissions come with truthmakers (or satisfiers) (Fine to 2018a, b; Moltmann 2017a, 2018a).

\section{The predicate is the case}

The predicate is the case appears to be a predicate synonymous with the truth predicate is true. However, is the case has a very different semantics, one in which the contribution of the noun case plays a central role, with its involvement of the truthmaking relation, the Actuality Condition, and the Case Space Requirement.

There is first of all a syntactic difference between is the case and is true. ${ }^{37}$ Is the case is a syntactic predicate that allows as subject only a that-clause or a pronoun such as that, as in $(67 \mathrm{a}, \mathrm{b})$, but not an ordinary $\mathrm{NP}$ as in $(67 \mathrm{c})$, in contrast to is true, as in $(67 \mathrm{~d})^{38}$ :

(67) a. That it is raining is not the case.

b. John feared that it might rain. That was in fact the case.

c. * John's claim is the case.

d. That it is raining/That/John's claim that $\mathrm{S}$ is true.

Is true can act as a predicate of truthbearers like claims, but not so for is the case. Yet with that-clauses as in (68), the case and is true appear to mean the same thing ${ }^{39}$ :

(68) a. That it is raining is the case.

b. That it is raining is not true.

\footnotetext{
37 See also Moltmann (2015a).

38 One might think that the case unlike true does not have the status of a predicate. However, standard linguistic criteria diagnose (is) the case as a predicate syntactically. First, the case like true can be the predicate in small-clause constructions, a standard criterion for predicatehood:
}

(i) a. I consider [it true that John is a genius].

b. I consider [it the case that John is a genius].

Second, like true, the case can combine with other copula verbs than be, such as remain and seem, again a criterion for predicatehood:

(ii) a. That John is the best player will always remain the case.

b. The generalization remained true despite the changing circumstances.

(iii) a. That John is happy does not seem the case.

b. That John is happy does not seem true.

39 This assumption is a hallmark of the deflationist view of truth (Horwich 1990), according to which 'the key idea [...] is that there seems no reason to distinguish being true from being the case. If there is no distinction between being true and being the case, presumably there is also no distinction between 'It is not the case that $p$ ' and 'It is not true that $p$ ', (Stoljar and Damnjanovic 2014).

Is the case is often regarded a redundant expression even by philosophers that do not share the deflationist view of truth. An exception is Mulligan and Correira (2017) for whom is true is a predicate applying to propositions and is the case a predicate applying to states of affairs. This appears mistaken, though, since is the case cannot actually apply to terms of the sort that state of affairs. 
However, there are significant semantic differences between is true and is the case with that-clauses. Those differences are, for some reasons, not as well reflected in English as, say, in German with ist der Fall 'is the case' and ist wahr 'is true', which I will therefore focus on. ${ }^{40}$ The most important semantic differences concern adverbial modifiers. ${ }^{41}$

First, ist wahr and ist der Fall differ in their acceptance of location modifiers. Location modifiers are perfectly fine with ist der Fall, but are often hard to make sense of with ist wahr:

(69) a. In unserer Firma ist es nicht der Fall, dass Angestellte ohne Erklärung entlassen werden.

'In our firm, it is not the case that employees get fired without explanation.'

b. ??? In unserer Firma ist es nicht wahr, dass Angestellte ohne

Erklärung entlassen werden.

'In our firm, it is not true that employees get fired without explanation.'

(70) a. In Hans' Familie ist es nicht der Fall, dass Kinder ihre Eltern respektieren. 'In John's family, it is not the case that children respect their parents.'

b. ??? In Hans' Familie ist es nicht wahr, dass Kinder ihre Eltern respektieren.

'In John's family, it is not true that children respect their parents.'

Whereas (69a) and (70a) are perfectly natural as statements of facts, (69b) and (70b) are hardly acceptable or at least convey a particular metasemantic notion of location-relative truth.

Furthermore, ist der Fall is fine with adverbs of quantification, with which ist wahr is hardly acceptable or at least conveys a particular metasemantic notion of time-relative truth:

(71) a. Es ist immer mehr der Fall, dass der Alzheimerpatient etwas vergißt.

'It is more and more the case that the Alzheimer patient forgets something.'

b. ??? Es ist immer mehr wahr, dass der Alzheimerpatient etwas vergißt.

'It is be more and more true that the Alzheimer patient forgets something.'

(72) a. Es war zweimal der Fall, dass jemand von der Versammlung abwesend war.

'It was twice the case that someone was absent from the meeting.'

b. ??? Es war zweimal wahr, dass jemand von der Versammlung abwesend war.

'It was twice true that someone was absent.'

In contrast to ist der Fall, with ist wahr, the subject clause needs to be (more or less) truth-conditionally complete, that is, complete regarding context-dependent elements (such as quantifier restrictions and temporal or spatial locations).

A further difference between is true and is the case shows up with adverbs that may act as degree quantifiers such as German kaum 'hardly'. With is the case, such

\footnotetext{
40 This may be because English is true is actually polysemous, permitting also a use equivalent to is the case.

41 These differences are discussed already in Moltmann (2015a).
} 
adverbs can act only as adverbs of quantification, whereas with is true they most naturally act as degree modifiers:

(73) a. Es ist kaum der Fall, dass Hans Kaffee trinkt.

'It is hardly the case that John drinks coffee.'

b. ??? Es ist kaum wahr, dass Hans Kaffee trinkt.

'It is hardly true that John drinks coffee.'

Whereas (73a) means that there are only rare cases of John drinking coffee, (73b) means something like 'it can hardly be said that John drinks coffee'.

The semantics of is the case involves quantification over truthmakers, that is, exact truthmakers. That exact truthmaking is involved is apparent from the way adverbs of quantification are understood ${ }^{42}$ :

(74) a. It was twice the case that John made a mistake.

b. It was only once the case that John lost the game.

c. It was three times the case that John or Mary received a gift.

Twice in (74a) counts those and only those situations that are completely relevant for the truth of John made a mistake, that is, situations that include nothing but John, a single mistake, and the make-relation holding between the two. Twice does not count any larger situations. Similarly, once in (74b) counts just situations of a single event of John's losing the game, not any larger situations. Finally, three times in (74c) counts situations in which either John or Mary received a gift. It does not count larger situations or sums of such situations. ${ }^{43}$ Adverbs of quantification with

\footnotetext{
42 This recalls Lewis (1975) use of 'case' in connection with adverbs of quantification, though for Lewis cases are n-tuples consisting of objects and relations.

Adverbs of quantification actually do not strictly count cases, but epistemic situations correlated with cases. Thus (i) appears false:
}

(i) It is a billion times the case that someone is Indian.

Moreover, (iia) appears true, as opposed to (iib):

(ii) a. It is more often the case that a natural number is even than it is prime.

b. It is as often the case that a number is prime as it is that it is even.

That adverbs of quantification quantify over epistemic situations is not restricted to case-sentences, given the intuitive truth of (iii):

(iii) A natural number is more often even than prime.

This means that the standard treatment of adverbs of quantification as unselective quantifiers ranging over n-tuples of entities (Lewis' 'cases') is not generally adequate.

43 As with nominal case-constructions, there are also conditions on the individuation of situations at play, though it is hard to tell whether they are due to the count status of times rather than the meaning of case:

(i) It was three times the case that John made more than one mistake.

Sentence (i) counts situations that are independently individuated and as such contain a particular number of mistakes. 
is the case do not count non-worldly facts, which could be quantificational and disjunctive. Otherwise, there would only be a single fact to be counted in (74a) and (74c).

The predicate is the case itself does not involve reference to a particular case, but rather, in the absence of an adverb of quantification, involves existential quantification over cases. This is clear from the interpretation of is the casesentences in the scope of negation and in the antecedent of a conditional:

(75) a. It is not the case that a student failed the exam.

b. If it is the case that a student fails the exam, then that student should be given the chance to repeat it.

(75a) states that there is no situation that makes the sentence a student failed the exam true. Also (75b) involves existential quantification over cases as part of the evaluation of the antecedent.

Is the case clearly carries the Actuality Condition since is the case (in extensional contexts) does not involve quantification over merely possible situations (which, recall, would be permitted by existential quantification in natural language as well as the truthmaking relation).

Moreover, is the case comes with the Case Space Requirement. The Case Space Requirement manifests itself in that is the case is hardly acceptable when it is not in the scope of negation, the antecedent of a conditional, or the scope of an adverb of quantification (in contrast, of course, to is true):

(76) a. ?? It is the case that it is raining.

b. It is not the case that it is raining.

c. If it is the case that it is raining, we need an umbrella.

d. It was sometimes the case that it was raining.

(76a) involves an assertion that will not set up a case-space. ${ }^{44}$ By contrast, the scope of negation in (76b) and the antecedent of the conditional in (76c) are associated with states of consideration, which do set up a case space. ${ }^{45}$ In (76d), sometimes ranges over a domain of situations (with or without rain), which forms a case space.

\footnotetext{
44 The acceptability of That $\mathrm{S}$ is the case improves with the addition of adverbials like in fact:

(i) It is in fact the case that it is raining.
}

That is because in fact is indicative of a background state of uncertainty, which sets up a case space that can fulfill the Case Space Requirement.

45 Not also associates with focus, in which case it is the focus-semantic value of its scope that sets up the case space:

(i) It is not the case that évery student failed the exam. 
The truth conditions of is the case-sentences involve reference to an epistemic state and existential quantification over truthmakers, as below ${ }^{46}$ :

(77) It is the case that $\mathrm{S}$ is true in a context $\mathrm{c}$ iff for some situation $\mathrm{s}$ and the epistemic state e associated with $\mathrm{c},<\mathrm{s}, \mathrm{CS}(\mathrm{e})>\in[\text { case }]^{\mathrm{c}}$.

Here case stands for the very same relation between situations and case spaces as when it occurs as the head of an NP.

Compositionally, the semantics of an is the case-sentence can be obtained by construing the relation between the that-clause and the is the case-predicate as one of higher-order predication. The is the case-predicate itself will then denote the set of sets in (78a), and the is the case-sentence will have the truth conditions in $(78 b)^{47}$ :

(78) a. [is the case $]^{\mathrm{c}}=\left\{\mathrm{X} \mid \exists \mathrm{s}\left(\mathrm{s} \in \mathrm{X} \&<\mathrm{s}, \mathrm{CS}\left(\mathrm{d}_{\mathrm{c}}\right)>\in[\text { case }]^{\mathrm{c}}\right)\right\}$

b. That $\mathrm{S}$ is the case is true in a context $\mathrm{c}$ iff $[\mathrm{S}]^{\mathrm{c}} \in[\text { is the case }]^{\mathrm{c}}$.

A location modifier will act as a predicate of the situations the is the casesentence will quantify over ${ }^{48}$ :

(79) $[\text { in NP is the case }]^{\mathrm{c}}=\left\{\mathrm{XI} \exists \mathrm{s}\left(\mathrm{s} \in \mathrm{X} \&<\mathrm{s},[\mathrm{NP}]^{\mathrm{c}}>\in[\text { in }]^{\mathrm{c}} \&<\mathrm{s}, \mathrm{CS}\left(\mathrm{d}_{\mathrm{c}}\right)>\right.\right.$ $\left.\left.\in[\text { case }]^{\mathrm{c}}\right)\right\}$

An adverb of quantification such as sometimes will itself introduce a quantifier binding the situation variable introduced by case, just as adverbs of quantification do with indefinites, when taken to be unselective quantifiers (Lewis 1975) ${ }^{49}$ :

[is Q-times the case $]^{\mathrm{c}}=\left\{\mathrm{X} \mid\right.$ for Q-many s: $\left.\mathrm{s} \in \mathrm{X} \&<\mathrm{s}, \mathrm{CS}\left(\mathrm{d}_{\mathrm{c}}\right)>\in[\text { case }]^{\mathrm{c}}\right\}$

\footnotetext{
46 The semantics of it is the case that $\mathrm{S}$ recalls the semantics that Austin (1950) proposed for independent sentences in general. On Austin's view, with the utterance of a sentence, a speaker refers to an (actual) situation and claims that the situation referred to is of the type specified by the sentence uttered. The situation referred to with the utterance of a sentence thus is meant to be a truthmaker of that sentence. On the present view, this is only part of the constructional meaning of is the case. With is the case, adverbs of quantification range over 'cases' and location adverbials act as predicates of cases.

Austin's motivations for implicit reference to situations were of course quite different from the present ones. The situation referred to, for Austin, is responsible for contextual restrictions on quantification domains, the interpretation of tense etc. The present motivation for invoking truth-making is the semantics of case-constructions.

${ }^{47}$ Of course, the sentence that $\mathrm{S}$ is the case should itself have a set of truthmakers as its meaning. Just as with conditionals, I will restrict myself here to just giving its truth conditions.

${ }^{48}$ Is the case with a location adverbial involves a condition of maximality: (69a) is about the maximal situation in the firm, not just some situation within the firm. This constraint is part of general conditions on individuating situations and imposed by the status of case as a count noun. Note that the situation in our firm, with the count noun situation, is generally also understood as referring to the maximal situation in the firm (unless a particular contextually relevant situation is meant).

${ }^{49}$ The semantics of the is the case-predicate raises similar issues for compositionality as indefinites or the Davidsonian event argument, being represented by a variable that can be bound either by adverb of quantification or an existential quantifier, issues that I will not address further in this paper.
} 
Note that on this analysis, the definite determiner is the case makes no semantic contribution, only the noun case does. That is because the case in that context does not have the status of a referential NP. Several diagnostics show that. First, the case in it is the case does not permit any other determiner than the simple definite determiner:

(81) a. * It is not that case that $\mathrm{S}$.

b. * It is not a case that $\mathrm{S}$.

Second, it does not permit adjectival or relative-clause modifiers:

(82) a. * It is not the improbable case that $\mathrm{S}$.

b. * That $\mathrm{S}$ is not the case that we expected.

Third, it cannot act as the antecedent of a case-anaphor:

(83) That no one comes to the party might be the case. ?? But we would not like that case.

The case in is the case rather appears to be a referential residue with the acting as a pleonastic determiner. ${ }^{50}$

\section{Conclusion}

In everyday speech, talk about 'cases' is abundant, and it is surprising that constructions with the noun case (or similar nouns in other languages) have received close to no attention in the linguistic or philosophical literature. Case-constructions

50 There is a potential alternative analysis of is the case-sentences that one might think of, namely as specificational sentences (Higgins 1979), sentences of the sort below:

(i) a. That John is innocent is the truth.

b. That we would all go is the idea.

c. That one can walk home is the advantage.

d. That John is incompetent is the problem.

There are some major differences, however, between is the case-sentences and specificational sentences. One difference is that is the case-sentences do not permit extraposition, unlike specificational sentences:

(ii) a. * It is the truth that John is innocent.

b. * It is the idea that we would all go.

Moreover, is the case-sentences do not permit inversion, unlike specificational sentences:

(iii) a. The truth is that $\mathrm{S}$.

b. The idea is that $\mathrm{S}$.

c. * The case is that $\mathrm{S}$.

Thus, an analysis of is the case-sentences as specificational sentences is hardly an option. 
bear significantly on central issues in contemporary semantic theory and philosophy of language, most importantly the notion of a possible situation or world, as well as the recent theoretical developments of truthmaker semantics and alternative semantics.

The semantics of case-constructions with its two distinct sources of case spaces gives a broader motivation for alternative semantics. Alternative semantics is generally pursued as a formal semantic theory of a range of constructions that explains their particular linguistic behavior. The semantics of case-constructions make clear that alternative semantics is just as much a matter of the semantics of the mind, specifically that of states of uncertainty, consideration, or inquiry.

The overall theoretical importance of case-constructions raises the question of how general those constructions are across languages. As a matter of fact, not all languages have case-constructions. Chinese lacks them, as do some European languages, such as Danish and Swedish. Even though case-constructions are not universal, the ingredients of their semantics should be, namely the truthmaking relation, situations with their conditions of individuation, sententially and epistemically determined alternatives, kind reference, and the lexical Actuality Condition.

Reference to situations with the noun case raises a more general and important issue, namely the ontological status of possibilities (possible worlds or situations), without which the semantics of conditionals, modals, and perhaps attitude reports seems hardly possible. In natural language semantics, it is common to posit possible worlds as parameters of evaluation, for the purpose of the semantics of modals, conditionals, and attitude reports. As parameters of evaluation, possible worlds are often considered 'mere posits' by the theorists, not involving an ontological commitment on the part of the language use. There are also good grounds, however, for attributing parameters of evaluation the same cognitive status as referents of referential NPs since a grasp of entities acting as parameters should be part of knowing the truth conditions of sentences and the meaning of relevant constructions. It is then expected that there should be explicit, non-technical terms for such entities in at least some languages. It appears that at least in English there aren't any terms in the core (non-technical part) of language that stand for entire worlds. ${ }^{51}$ Case-constructions clearly belong to the core (non-technical part) of language, and they indicate that what is involved in the semantics of conditionals, attitude reports, and epistemic modals are not worlds, but situations, and that in their role as truthmakers.

Acknowledgements The paper has benefitted from the audiences at presentations of material of this paper at the Conference Truth Makers and Proof Objects, organized by P. Martin-Loef, École Normale Supérieure, Paris (2011), Kit Fine's seminar Truthmaker Semantics at NYU (2012), the City University of Hong Kong (2012), the University of Göttingen (2012), the University of Chicago (2012), the workshop Truth, Existence and Fundamentality, organized by T. Sattig and A. Torza, Tübingen (2013), the University of Padua (2013), the Symposium on Truthmaking, organized by M. Traynor, Arché, St Andrews (2014), the University of Düsseldorf (2018), the New York Philosophy of Language Workshop at

\footnotetext{
51 Of course, there is the term possible world, used by theorists to refer to entire possible worlds. However, even though a legitimate part of English, possible world is a 'technical' term in the (ontological) periphery, not the core of language. See Moltmann (to appear a) for the core-periphery distinction relevant for natural language ontology.
} 
NYU (2019), and the conference Truthmmaker Semantics: Applications in Philosophy and Linguistics, organized by S. Kraemer, Hamburg (2019). I would like to thank the audiences for lots of fruitful discussions. I would also like to thank Lucas Champollion, Richard Kayne, Adam Przepiórkowski, Craige Roberts, Susan Rothstein, and especially Kit Fine for comments on previous versions of this paper and stimulating discussions of the material.

Open Access This article is distributed under the terms of the Creative Commons Attribution 4.0 International License (http://creativecommons.org/licenses/by/4.0/), which permits unrestricted use dis tribution, and reproduction in any medium, provided you give appropriate credit to the original author (s) and the source, provide a link to the Creative Commons license, and indicate if changes were made.

\section{Appendix 1: Nominal case-NPs}

This appendix will discuss case-NPs with nominal modifiers rather than clausal ones and suggest an extension of the truthmaker-based semantic analysis of clausal caseNPs to them.

\section{Property-related and object-related cases}

The case-NPs below seem to have a semantics quite different from that of case-NPs with clausal modifiers, which have been the focus of this paper:

(1) a. a case of flu

b. the case of the stolen statue

Case-constructions of the sort in (1a) stand for instances of universals, which can be called property-related cases. Case-constructions as in (1b) refer to cases tied to particular objects, which can be called object-related cases.

There are good reasons not to posit an ambiguity in the word case in nominal and clausal case-constructions. First of all, the European languages that have caseconstructions (such as English, Italian, French, and Spanish) generally display all three constructions, clausal case-NPs and the two types of nominal case-NPs in (1). ${ }^{52}$ Moreover, case in all three constructions displays the Actuality Condition and the Case Space Requirement. The two nominal case-constructions moreover are semantically close to each other since they may describe the very same cases, as below:

(2) a. The case of the new cancer patient is a case of stage 2 cancer.

b. The case of the missing statue just is the case of the recent museum theft.

Property-related cases may be medical cases, legal cases, or manifestations of particular types of behavior or art movements ${ }^{53}$ :

\footnotetext{
52 By contrast, the word for case as in briefcase translates very differently in those languages.

53 In French, property-related cases may be described with bare plurals, as below (de Velde (ms)):

(i) J'ai connu des cas de journalistes honnêtes.

'I knew of cases of honest journalists.'
} 
(3) a. This is a case of insanity.

b. What John has is a case of schizophrenia.

c. The incident is a case of fraud.

d. John's behavior toward Mary is a case of harassment.

e. This building is an unusual case of art deco.

Property-related cases are often tropes, as in (3a) and perhaps (3b, c, d), but may also be objects, it appears, as in (3e). ${ }^{54,55}$

Typical object-related cases are generally restricted to contexts of medicine or law. ${ }^{56}$ Further examples of object-related cases are those below:

(4) a. the case of that incident

b. the case of the man that has suffered from this illness for more than 20 years

c. the case of the stolen statue

A property-related case has generally very different sorts of properties than what I will call its correlated object and should be considered an entity distinct from it. ${ }^{57}$

First, a case and its correlated object display different readings of predicates expressing object-related attitudes, and that whether the correlated object is a material object, a trope, or an event:

(5) a. Mary thought about the case of the disabled student.

b. Mary thought about the disabled student.

c. Mary thought about the disability of the student.

(6) a. The coach remembered an unexpected victory.

b. The coach remembered the case of an unexpected victory.

(5a), (5b) and (5c) mean different things. Unlike (5b) and (5c), understanding (5a) requires understanding what sort of case the case is meant to be, a legal or medical case, for example. What case it is depends on which features of the student or his disability are relevant, from a medical or legal point of view, for example. Those features will be constitutive of the medical or a legal case. Importantly, the features may include not only intrinsic properties of the object in question, but also relations it enters to other entities. No identification of relevant features is required for $(5 b)$ and

\footnotetext{
54 Trope-like cases appear to have inspired Woltersdorff's (1970) use of the noun case for tropes.

55 However, not all instances of universals are cases. For example, for an instance of a universal to be a case, it needs to have a particular complexity that does not make it too obviously an instance of the universal. Whiteness and darkness do not have instances that are cases (?? a case of whiteness, ?? a case of darkness), but insanity, fraud, and honesty do.

${ }^{56}$ Legal cases are also associated with a special case-construction in English of the sort the case Dominique Strauss-Kahn, which is a close apposition and syntactically distinct from the construction in (1b).

57 The construction the city of Munich does convey an identity relation between the referent of the complement and the referent of the entire NP. But this is not so for object-related case-NPs.
} 
(5c), where the object of study may simply be the student himself or his disability. ${ }^{58}$ In (6a) the coach is likely to remember the details of the victory (as experienced by himself), whereas in (6b) it suffices entirely that the coach remembers just the fact that a victory happened (which she probably was not involved in).

Cases and their correlated objects differ also when acting as objects of discussion and evaluation:

(7) a. We discussed the case of the book.

b. We discussed the book.

(8) a. The case of the stolen statue is interesting.

b. The stolen statue is interesting.

c. The theft of the statue is interesting.

(9) a. John compared the case of the first student to the case of the second student.

b. John compared the first student to the second student.

Again case-terms require the identification of relevant features of the correlated object making up the kind of case in question.

Finally, cases and their correlated objects generally have different part-whole structures. A case does not inherit its part-structure from its correlated object. Thus, (10a) has a different meaning from (10b), which is about the parts of an artifact, and from (10c), which is about the (temporal) parts of an event:

(10) a. Part of the case of the stolen statue is familiar.

b. Part of the stolen statue is familiar.

c. Part of the theft of the stolen statue is familiar.

The part structure of a case involves not spatial, functional, or temporal parts, but rather parts based on the 'information content' of the situation made up from the relevant properties (intrinsic or relational) holding of the correlated object.

Thus, object-related cases are ontologically distinct from the correlated objects if the latter are material objects or events. The understanding of evaluative properties and the part structure of object-related cases indicate that object-related cases are on a par with cases that are situations acting as truthmakers of sentences, motivating a unified account of cases described by clausal and object-related case-NPs. Objectrelated cases carry just those properties relevant for verifying that the correlated object meets the contextually given condition. For the semantics of object-related case-terms, sentences are not available; instead simple propositions of the form $<\mathrm{P}$, $\mathrm{o}>$ can serve as the entities that truthmakers stand in the truthmaking relation to, where $\mathrm{P}$ is a contextually given property of the relevant legal or medical type. The noun case in object-related case-NPs will also involve a case space, a set $\mathrm{X}$ of alternative situations $\mathrm{s}, \mathrm{s} \Vdash<\mathrm{P}, \mathrm{d}>$ for a suitable object $\mathrm{d}$. An object-related casenominal will then have the semantics below:

\footnotetext{
58 An object-related case thus involves a filtering condition regarding the correlated object, which determines which properties or relations are constitutive of the object-related case. This condition may be called an ontological case filter mimicking the more familiar, but unrelated, syntactic notion of a 'Case Filter' of Chomsky (1981).
} 
(11) For a context $\mathrm{c}$, [case of the stolen statue $]^{\mathrm{c}}=\left\{<\mathrm{s}, \mathrm{X}>\mid<\mathrm{s}, \mathrm{X}>\in[\text { case }]^{\mathrm{c}}\right.$ \& $\mathrm{s} \Vdash<\mathrm{P}$, [the stolen statue $\left.]^{\mathrm{c}}>\right\}$

Given that object-related cases can be identical to property-related cases, a property-related case nominal would have the semantics below, where $X$ is a set of situation $\mathrm{s}, \mathrm{s} \Vdash<[$ theft $], \mathrm{d}>$ for objects $\mathrm{d}$ in a suitable contextually given set $\mathrm{A}_{\mathrm{c}}:{ }^{59,60}$

(12) For a context $\mathrm{c}$, [case of theft $]^{\mathrm{c}}=\left\{<\mathrm{s}, \mathrm{X}>\mid \exists \mathrm{d}\left(\mathrm{d} \in \mathrm{A}_{\mathrm{c}} \&<\mathrm{s}, \mathrm{X}>\in[\text { case }]^{\mathrm{c}}\right.\right.$ $\& \mathrm{~s} \Vdash<[$ theft $], \mathrm{d}>)\}$

Object-related cases may differ from their correlated objects in yet other respects. Generally, it is difficult for a case to have properties of concreteness. Thus, cases generally do not have a spatial location, even if their underlying object has one:

(13) a. ??? The case of the stolen statue is on the table.

b. The statue is on the table.

Event-related cases, moreover, do not have the temporal properties of the correlated events, such as having a duration or being sudden:

(14) a. A snowfall might be long-lasting/sudden.

b. ?? The case of a snowfall might be long-lasting/sudden.

A case of an event no longer has the temporal structure of the correlated event.

In addition, cases generally do not act as objects of perception:

(15) a. ??? I saw/noticed the case of the broken vase.

b. I saw/noticed the broken vase.

Finally, cases generally are not causally efficacious (except, of course, as objects of mental attitudes):

(16) a. An overweight baby caused the cradle to break apart.

b. ?? The case of an overweight baby caused the cradle to break apart.

59 A somewhat different treatment is required when case occurs predicate-initially, as below:

(i) John's illness is a case of cancer.

It is plausible that (i) is not an ordinary subject-predicate sentence, but rather is on a par with (ii):

(ii) Wisdom is a property not many people have.

The predicate in (ii) arguably does not just attribute a property to the semantic value of the subject, but involves its reification as a property object (Moltmann 2013a, Chapt. 6). Similarly, the predicate in (i) would involve 'filtering' of the subject referent as a case.

60 For property-related cases a more direct semantics may be available once truhmaking is extended from a relation of an entity to a sentence or epistemic state to a relation of an entity to a property (Fine, p.c). The latter relation should not be understood as instantiation, though. Instantiation is generally taken to be either a relation between tropes and properties or between objects and properties. But cases are neither tropes nor objects. 
These restrictions are expected if cases are on a par with worldly facts, rather than material objects or events. ${ }^{61}$ Events are spatially located, have a temporal structure and duration, and enter causal relations, but not facts, at least not on a common view. ${ }^{62}$

\section{Appendix 2: Cases and the truthmaker debate in metaphysics}

Fine's notion of truthmaker in 'truthmaker semantics' differs from the use of 'truthmaker' in metaphysics. Truthmaking in the sense of Fine and in the sense relevant in the context of this paper is simply the relation between a situation $\mathrm{s}$ and a sentence $S$ such that $s$ makes $S$ true and is wholly relevant for the truth of S. Truthmaking in a different sense is a central topic of discussion in contemporary metaphysics and concerns the question whether the truth of a sentence needs to be grounded in ultimate reality, and in particular grounded in entities, that is, in truthmakers. Advocates of truthmaking for the grounding of truth generally do not assume that the truthmaking relation plays a role in the semantics of natural language itself. The metaphysical interest in truthmaking is completely different from that of truthmaker semantics in the sense of Fine, where the truthmaking relation only serves semantic purposes and truthmakers are not necessarily part of the world, but include both actual and possible (and even impossible) situations. Truthmakers thus are not meant to be part of what there ultimately is or to 'carve reality at its joints'. Truthmaker semantics, however, can be used so as to address the metaphysical question of the grounding of truth, by restricting it to sentences that are in fact true and taking only actual situations to be truthmakers (even if they

\footnotetext{
61 The restrictions are not strict, though. Under special circumstances, object-related and property-related cases appear to act as objects of perception and relata of causal relations:
}

(i) a. This case of musical experimentation sounds horrible.

b. This one case of cholera/The case of that cholera infection was the cause of a great epidemic.

Cases described by nominal case-terms may differ from worldly facts also in that they may go along with the existence predicate exist or the existence predicate happen, unlike cases described by clausal case-terms, which have their own special existence predicate:

(ii) a. The case of the cancer patient that Mary described exists/??? occurred/??? presented itself.

b. That case of fraud happened yesterday.

Here object-related cases inherit their mode of existence from the correlated object. Similarly, objectrelated and property-related cases may inherit perceptual or causal properties from the correlated objects. Perhaps case has another, related meaning, allowing nominal case-NPs to describe objects reduced to only some of their properties, those fulfilling the condition in question. Such 'filtered objects' are like the original objects, but they will have only some of the properties of the original objects, such as their modes of being and a filtered object would be something in between a 'thin particular' and a 'thick particular' in Armstrong's (1997) sense. See also Moltmann (2017b).

62 Note, though, that in Situation Semantics, situations (worldly facts) have been considered objects of (immediate) perception (Barwise and Perry 1981). 
are not part of ultimate reality). Cases as truthmakers might then shed some light on the issue of the nature of truthmakers that the philosophical debate raises.

Some philosophers, in particular Mulligan et al. (1984) and Lowe (2006), take truthmakers to be fully individuated entities that play an independent role in the world, for example as objects of perception and relata of causal relations. Truthmakers on their view are events, tropes, and objects. ${ }^{63}$ An event of John's walking, for example, would be a truthmaker of the sentence John walked, and John himself the truthmaker of the sentence John exists. A potential difficulty for that view may be that fully individuated entities cannot fulfill the condition of exact truthmaking. There are always features about a particular walk, for example, that may not be relevant for the truth of John walked (for example the location of the walk and the way the walking was performed), and there are various aspects of John not relevant for the truth of John exists. One may want truthmakers for exact truthmaking to be thinner than or at least different from fully individuated objects. This is what the notion of a situation or case appears to. Situations or cases are primarily part of the world, not entities in the world.

Another potential difficulty for the view that truthmakers are ordinary objects is that it is not compatible with presentism, the view that only objects at the present moment exist (Sider 2001; Merricks 2007). Given presentism, most true sentences will fail to have a truthmaker or will at some point lose their truthmaker if truthmakers are entities of the sort of events, tropes, and objects. Truthmakers conceived of as situations or 'cases', by contrast, appear to be compatible with presentism. Cases are entities that exist not in time, but time-independently-and thus, derivatively, at any time. This is reflected in the use of tense in natural language. Existential quantification over cases whose correlated objects are past events is possible with present tense. By contrast, existential quantification over past events requires past tense. Talking about events in the past, (1a) and (2a) are perfectly fine (that is, possibly true); but (1b) and (2b) are not, as opposed to (1c) and $(2 c)$ :

(1) a. There are at least three cases of this disease.

b. ??? There are at least three outbreaks of this disease.

c. There were at least three outbreaks of the disease.

(2) a. There are only three cases in which someone managed to cross the border.

b. ??? There are only three crossings of the border.

c. There were only three crossings of the border.

Cases are situations constituted by the holding of tensed properties or relations. As such, they will exist not relative to a particular time; but at any time.

There is another type of object-related entity that shows the same timeindependence as event-related cases. These are entities constituted by the lasting legacy of a person, such as philosophical or literary figures. Below, we see that

\footnotetext{
63 Events and tropes also act as truthmakers in Moltmann (2007), where truthmaking is applied to the semantics of event and trope nominalizations and the semantics of adverbials.
} 
present tense can be used to quantify over philosophical figures that (as persons) no longer exist, which is not possible with entities viewed simply as persons:

(3) a. There are three famous philosophers that had studied in Tübingen, Hegel, Fichte and Schelling.

b. ??? There are three people that had studied in Tübingen and became famous philosophers, Hegel, Fichte, and Schelling.

c. There were three people that studied in Tübingen and became famous philosophers, Hegel, Fichte, and Schelling.

Philosophical figures are ontologically distinct from the actual persons; they are something like persons reduced to their philosophical views and achievements. As such, they share their time-independent existence (once they have come into existence in the first place) with cases.

\section{References}

Aloni, M. (2007). Free choice, modals and imperatives. Natural Language Semantics, 15, 65-94. Armstrong, D. (1997). A world of states of affairs. Cambridge: Cambridge University Press.

Armstrong, D. (2004). Truth and truthmakers. Cambridge: Cambridge University Press.

Austin, J. L. (1950). 'Truth'. Aristotelian Society Supplement, 24, 111-129. (Reprinted in Philosophical papers, by J. O. Urmson \& G. J. Warnock, Ed., Clarendon Press, Oxford).

Austin, J. L. (1961). Unfair to facts. In J. O. Urmson \& G. J. Warnock (Eds.), Philosophical papers (pp. 102-222). Oxford: Clarendon Press.

Barwise, J., \& Perry, J. (1981). Semantic innocence and uncompromising situations. Midwest Studies in Philosophy, 6(1), 387-404.

Carlson, G. (1977a). A unified analysis of the English bare plural. Linguistics and Philosophy, 1, 413457.

Carlson, G. (1977b). Amount relatives. Language, 53, 520-542.

Chomsky, N. (1965). Aspects of the theory of syntax. Cambridge, MA: MIT Press.

Chomsky, N. (1981). Lectures on government and binding. Dordrecht: Foris.

Ciardelli, I., Roloefsen, F., \& Theiler, N. (2017). Composing alternatives. Linguistics and Philosophy, 40, $1-36$.

Cinque, G. (2015). Three phenomena discriminating between "raising" and "matching" relative clauses. Semantics-Syntax Interface, 2(1), 1-27.

Fine, K. (1982). First-order modal theories III: Facts. Synthese, 53, 43-112.

Fine, K. (2012). Counterfactuals without possible worlds. Journal of Philosophy, 109(3), 221-246.

Fine, K. (2014). Truthmaker semantics for intuitionistic logic. Journal of Philosophical Logic, 43(2-3), $549-577$.

Fine, K. (2017). Truthmaker semantics. In B. Hale, C. Wright, \& A. Miller (Eds.), A companion to the philosophy of language (Vol. 2, pp. 556-577). Oxford: Wiley-Blackwell.

Fine, K. (2018a). Compliance and command I. Review of Symbolic Logic 11(4), 609-633.

Fine, K. (2018b). Compliance and command II. Review of Symbolic Logic 11(4), 634-664.

Hamblin, C. L. (1973). Questions in Montague English. Foundations of Language, 10(1), 41-53.

Higgins, R. (1979). The pseudo-cleft construction in English. Bloomington: Indiana University Linguistics Club.

Horwich, P. (1990). Truth. Oxford: Blackwell.

Karttunen, L. (1972). Possible and must. In J. Kimball (Ed.), Syntax and semantics (Vol. 1, pp. 1-20). New York: Academic Press.

Kayne, R. (1994). The antisymmetry of syntax. Cambridge, MA: MIT Press.

Kayne, R. (2010). Why isn't this a complementizer? In R. Kayne (Ed.), Comparisons and contrasts (pp. 190-227). Oxford: Oxford University Press. 
Kratzer, A. (2002). Facts: Particulars or information units. Linguistics and Philosophy, 25(5-6), 655-670.

Kratzer, A. (2014). Situations in natural language semantics. In E. Zalda (Ed.), The Stanford encyclopedia of philosophy (Spring 2014 edition). https://plato.stanford.edu/archives/spr2014/entries/situationssemantics/.

Kratzer, A., \& Shimoyama, J. (2002). Indeterminate pronouns: The view from Japanese. In Y. Otsu (Ed.), Proceedings of the third Tokyo conference on psycholinguistics (pp. 1-25). Tokyo: Hituzi Syobo.

Lewis, D. (1975). Adverbs of quantification. In E. Keenan (Ed.), Formal semantics of natural language (pp. 178-188). Cambridge: Cambridge University Press.

Lowe, J. (2006). The four-category ontology. Oxford: Oxford University Press.

Merricks, T. (2007). Truth and ontology. Oxford: Clarendon Press.

Moltmann, F. (2007). Events, tropes and truthmaking. Philosophical Studies, 134, 363-403.

Moltmann, F. (2013a). Abstract objects and the semantics of natural language. Oxford: Oxford University Press.

Moltmann, F. (2013b). The semantics of existence. Linguistics and Philosophy, 36(1), 31-63.

Moltmann, F. (2014). Propositions, attitudinal objects, and the distinction between actions and products. Canadian Journal of Philosophy, 43(5-6), 679-701.

Moltmann, F. (2015a). Truth predicates in natural language. In D. Achourioti, et al. (Eds.), Unifying the philosophy of truth (pp. 57-83). Dordrecht: Springer.

Moltmann, F. (2015b). A predicativist semantics of modals based on modal objects. In T. Brochagen, F. Roloefson \& N. Theiler (Eds.), Proceedings of the 15th Amsterdam colloquium (pp. 296-302). Amsterdam: ILLC.

Moltmann, F. (2015c). Quantification with intentional and with intensional verbs. In A. Torza (Ed.), Quantifiers, quantifiers, and quantifiers (pp. 141-168). Dordrecht: Springer.

Moltmann, F. (2017a). Cognitive products and the semantics of attitude verbs and deontic modals. In F. Moltmann \& M. Textor (Eds.), Act-based conceptions of propositional content. Contemporary and historical perspectives (pp. 254-289). Oxford: Oxford University Press.

Moltmann, F. (2017b). On the ontology of cases. In N. Flaux, P. Haas, V. Mostrov, K. Paykina, \& F. Tayalati (Eds.), De la Passion du Sense en Linguistique. Hommage Á Daniéle van de Velde (pp. 171-186). Valenciennes: Presses Universitaires de Valenciennes.

Moltmann, F. (2018a). An object-based truthmaker semantics for modals'. Philosophical Issues, 28(1), $255-288$.

Moltmann, F. (2018b). Existence predicates. Synthese. https://doi.org/10.1007/s11229-018-1847-z.

Moltmann, F. (to appear a). Abstract objects and the core-periphery distinction in the ontological and conceptual domain of natural language. In J. L. Falguera \& C. Martinez (Eds.), Abstract objects. For and against. Dordrecht: Springer.

Moltmann, F. (to appear b). Variable objects and truthmaking. In M. Dumitru (Ed.), The philosophy of Kit Fine. New York: Oxford University Press.

Mulligan, K., \& Correira, F. (2017). Facts. In E. Zalta (Ed.), The Stanford encyclopedia of philosophy (Winter 2017 edition). https://plato.stanford.edu/archives/win2017/entries/facts/.

Mulligan, K., Simons, P., \& Smith, B. (1984). Truthmakers. Philosophy and Phenomenological Research, 44, 287-321.

Papafragou, A. (2006). Epistemic modality and truth conditions. Lingua, 116, 1688-1702.

Priest, G. (2005). Towards non-being: The logic and metaphysics of intentionality. Oxford: Oxford University Press.

Rooth, M. (1992). A theory of focus interpretation. Natural Language Semantics, 1(1), 75-116.

Santorio, P. (2018). Alternatives and truthmakers in conditional semantics. Journal of Philosophy, 115, 10.

Sider, T. (2001). Four-dimensionalism. Oxford: Oxford University Press.

Stalnaker, R. (1984). Inquiry. Cambridge: MIT Press.

Stoljar, D., \& Damnjanovic, N. (2014). The deflationary theory of truth. In E. Zalda (Ed.), The Stanford encyclopedia of philosophy (Fall 2014 edition). https://plato.stanford.edu/archives/fall2014/entries/ truth-deflationary/.

Strawson, P. F. (1949). Truth. Analysis, 9(6), 83-97.

Van de Velde, D. (ms). Cas et Fait. Ms University of Lille.

Vergnaud, J.-R. (1974). French relative clauses. Ph.D. Dissertation, MIT.

Von Fintel, K., \& Gillies, A. (2010). Must...stay...strong! Natural Language Semantics, 18, 351-383. 
Woltersdorff, N. (1970). On universals. Chicago: Chicago University Press.

Yablo, S. (to appear). Relevance without minimality. In A. Egan, P. van Elswyk, \& D. Kinderman (Eds.), Unstructured content. Oxford: Oxford University Press.

Publisher's Note Springer Nature remains neutral with regard to jurisdictional claims in published maps and institutional affiliations. 